Nit.si TM 81.558

N $80 \cdot 31399$.

NASA Technical Memorandum 81558

NASA-TM-81558 19800022893

\title{
REVERSE THRUST PERFORMANCE OF THE QCSEE VARIABLE PITCH TURBOFAN ENGINE
}

N. E. Samanich, D. C. Reemsnyder, and H. E. Bloomer Lewis Research Center Cleveland, Ohio

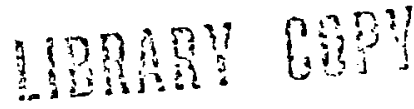

Prepared for the Aerospace Congress LAMCLEY RESEFECH CERTER sponsored by the Society of Automotive Engineers? Los Angeles, California, October 13-16, 1980 
-.

$\therefore$ 


\section{6}

SHORT-HAUL AIRCRAFT HAVE BFEN PROPOSED as one solution to a irport congestion 'a number of years ago. In principle, these aircraft would operate out of numerous existing short runway a irfields, and would thereby alleviate the increasing traffic problem at major terminals. In 1974, NASA-Lewis awarded a contract to The General Electric Company to design, fabricate and test two Ouiet, Clean, Short-Haul, Experimental Engines (QCSEE). One propulsion system was designed for an Under-theWing (UTW) externally blown flap application; the other was configured for Over-the-Wing (OTW) upper-surface blowing. Major objectives of the program were to develop the technology needed to meet the stringent noise, exhaust emissions, performance, wejght and transient thrust requirements of future short-haul aircraft. The contractor phase of the program was completed in 1978 and results reported in $(1,2)^{*}$.

Subsequently NASA-Lewis evaluated complete engine systems with representative powered-lift wing segments (3). Testing included acoustic evaluation of bulk absorber material (4), UTW reverse thrust and forwardto-reverse transient tests. Testing at Lewis was completed in 1979.

Noise requirements for short-haul a ircraft and the QCSEE program dictated that a low-pressure ratio, high-bypass ratio fan be used, especially for under-the-wing installation. Studies have indicated that for such installations, engines designed with variable-pitch fans for reverse thrust $(5,6)$ are superior to those with fixed pitch fans and conventional reversers. The potential advantage of using variable-pitch fans is the elimination of the conventional heavy, high-maintenance, target or cascade thrust-reversal hardware plus the added benefit of improved thrust response time $(5,6)$. One of the potential problems in operation of variable pitch fans is difficulty in establishing reverse thrust at certain reverse blade angles $(7,8)$. This problem is aggravated when reversing with forward velocity. However, operational techniques during forward-to-reverse transients, such as blade angle overshoot, have been shown to be effective in reducing the time to establish reverse thrust $(7,8)$.

During UTW engine steady-state reverse thrust tosting at General Electric, turbine temperature limit was reached before the reverse thrust goal of $35 \%$ of takeoff thrust, was achieved $(9,10)$. Al though removing the aft fan duct acoustic splitter improved the thrust $2 \%$, from $25 \%$ to $27 \%$ of takeoff thrust, further improvement was desirable. Early model tests (11) indicated that the fan nozzles, if flared to about 300 did provide reasonable pressure recovery when used as inlets. Later testing (12) showed that pressure recovery of these flared inlets could be adversely affected by serrations cut into the leading edge of the inlets. In the reverse position, the CCSFE fan nozzle is flared to about $30^{\circ}$, but sizeable openings exist between the four flaps and between the flaps and main nacelle in the hinge plane.

* Numbers in parentheses designate references at end of paper. 
In an attempt to evaluate the effect of those openings on reverse performance, a fixed $30^{\circ}$ half-angle conical exlet having the same flap length and trailing edge sharpness was fabricated and tested on the QCSEF: UTW engine. Steady-s tate reverse testing reported herein included backto-back tests with the fixed $30^{\circ}$ exlet and the movable flaps (RCSEE). The engine was tested over a range of fan speeds and reverse fan blade angles. Measurements inclucied thrust, fan and core speeds, fan blade angle, and pressure and temperature profiles before and behind the fan rotor and at the compressor face.

The NASA test program culminated with an evaluation of the forwardto-reverse thrust transient characteristics of the OCSEF engine. All transients included an automatic change in the oCSEE four-flap fan nozzle from a forward thrust setting (convergent nozzle) to an open, $\sim 30^{\circ}$ flare position for reverse. Simultaneously, the fan blades were rotated through "stall" from forward thrust fan blade angles $\left(\beta_{F}=+5\right.$ to $\left.-7^{\circ}\right)$ to reverse thrust blade angles $\left(\beta_{F}=-97\right.$ to $\left.-112^{\circ}\right)$. Transients were initiated from nominal forward idle, approach and takeoff power to various levels of reverse thrust. Other variations included final reverse blade angle, blade angle overshoot and fuel scheduling during the transients. Typical overall. sound pressure levels during the transients were also obtained.

This report discusses the results of steady-state reverse tests of two reverse inlet (exlet) configurations and forward-to-reverse transient tests of the QCSEE ITW engine conducted at the Lewis Research Center.

\section{UTW ENGINE CHARACTERISTICS}

The UTW engine is an advanced technology, experimental turbofan built around an existing advanced core. The technical advances emphasize such environmental factors as low noise and exhaust emissions. Performance is improved primarily by reducing engine wejght to achieve a high engine thrust-weight ratio.

UTW ENGINE DESIGN CHARACTERISTTCS - A summary of the OCSEF, UTW engine technical goals are presented in Table 1 for a four-engine conmercial transport aircraft. Because of the importance of low noise to any future aircraft and particularly short-haul powered-lift aircraft, very stringent goals were established with the takeoff and approach noise level set at $95 \mathrm{EPNdB}$. The under-the-wing engine installation results in direct impingement of the exhaust jet on the wing flap and the resulting, jet/flap interaction noise is a major contributor to the total noise signature. As shown in Fig. 1, a very low fan pressidre ratio (jet velocity) was required and was selected to keep this noise source about? $\mathrm{dB}$ below the total system noise for a balanced acoustic design.

The UTW experimental propulsion system shown in Fig. 2. was designed (13) to provide $81,400 \mathrm{~N}(18,300 \mathrm{lb})$ of uninstal. led thrust and $77,400 \mathrm{~N}$ $(17,400 \mathrm{lb})$ of installed forward thrust at takeoff on a $305.6 \mathrm{~K}\left(90^{\circ} \mathrm{F}\right)$ day. Reverse thrust goal was set at, $35 \%$ of forward takeoff thrust. 
Specific UTW engine features include: a composite structure high Mach (accelerating) inlet; a gear-driven, variable-pitch fan with composite fan blades; a composite fan frame; an acoustically treated fan duet with an ocoustic splitter ring; a variable-geometry fan exhaust nozzle, an advanced ( Flol) core engine and low prosaure turbine; an acoustically treated core exhaust, nozrle; top-mounted consine accossories; and a digital electronice control aystem combined with a hydromechanical ruel control. Critical aerodynamic design parameters are lisied in Table?. The UTW engine has a high bypass ratio of 11.8 and a low fan pressure ratio at takeof $f$ of 1.27 .

The UTW engine requires control of four variables; fuel flow, fan blade angle, fan nozzle area and core compressor stator angle. The control system incorporates two basic control components, a modified hydromechanical fuel control and an engine-mounted digital electronic control designed specifically for the QCSEE engines (14). A primary requirement of the control system was the capability of achieving a thrust response of $1.0 \mathrm{sec}$ for approach-to-takeoff thrust and 1.5 sec for approach-to-reverse thrust. During operation, fuel. flow controls engine pressure ratio (compressor discharge pressure/inlet total pressure variables closely related to thrust); fan blade angle controls fan speed, and the fan nozzle area controls inlet Mach number (a key inlet noise parameter). The fan blade variable pitch actuation system was a hydraulically powered ball spline design described in (13).

Acoustic design parameters are listed in Table 3 and acoustic features of the engine are shown in Fig. 3 .

UTW ENGINE PERFORMANCE CHARACTERISTTCS - A summary of previous GE and NASA test results $(1,3)$ is listed in Table 4 . Acoustic tests at NASA (3) of the UTW engine with representative powered-lift wing flap sections indicate peak $152 \mathrm{~m}$ ( $500 \mathrm{ft}$.) sideline noise of 98.5 and $99.7 \mathrm{EPNdB}$ at approach and takeoff, respectively along with a $2.59 \mathrm{sq} \mathrm{km}(1.0 \mathrm{sq}$. mile) 95 EPNdB contour area. Al though these values are above the 95 EPNdB and $1.29 \mathrm{sq} \mathrm{km}(0.5 \mathrm{sq} \mathrm{mile})$ contour area goals, they are substantially lower than any comnercial aircraft in service today.

The pollution, forward thrust, specific fuel consumption and thrustto-weight goals were all met or exceeded. Al though the UTW engine failed to meet the $610 \mathrm{~m}(2000 \mathrm{ft})$ runway reverse thrust goal of $35 \%$ of takeoff thrust, it did produce about $27 \%$ reverse thrust, and this might be sufficient to decelerate an aircraft on a $915 \mathrm{~m}$ (3000 ft.) runway. The approach-to-takeoff forward thrust transient was not attempted due to fan overspeed indications during lower power transients.

\section{APPARATUS AND PROCEDURE}

The UTW variable pitch turbofan engine was tested for reverse performance at a NASA Lewis outdoor engine test stand. Detailed instrumentation, data reduction, and test procedures were incorporated to define steady-state reverse thrust performance and forward-to-reverse thrust transient characteristics. 
TEST FACILITY - The enfine test stand (Fig. 4 and 5 ) was designed specificaliy for test of the OCSEF engines. Specific attention was given to the proximity of the ground plane and stand structure to the inlet and exit planes. These could cause flow turbulence and flow distortion resulting in high blade stress and/or noisc gencration. Engine centerline was 14.6 in $(15 \mathrm{ft})$ above grade. The stand had separable lower and upper structure. A compact "A" frame upper structure straddled and held the engine (top mounts) and all its accessories. The stand was designed to enable measurement of forward, reverse and side loads. The engine upper stand structure was hung from flexure plates and steadystate thrust was measured by load cells. The outdoor test stand was located at the NASA Lewis Engine Noise Test Facility immediately adjacent to $\mathrm{Cl}$ eveland Hopkins Airport.

ENGINE TEST CONFIGURATION - A schematic of the reverse thrust configuration along with engine station designations is shown in Fig. 6 and symbols are defined in Appendix A. In the reverse thrust mode, flow enters the engine at the fan nozzle (exlet), passes through the aft fan duct and fan bypass outlet guide vanes and then separates into two streams; one stream passing through the fan rotor and discharging out the engine inlet, and the other stream turning $180^{\circ}$ and entering the gooseneck to the core compressor. A photograph of the 6-foot diameter OCSEE fan rotor is shown in Fig. 7. Although the OCSEE design was capable of fan blade pitch change in either direction (Fig. 8), reverse through stall was found to provide improved performance (7) and therefore was used in these tests. In this direction the blades are "opened" about $100^{\circ}\left(\beta_{F}=-100^{\circ}\right)$ from the forward thrust design blade angle ( $\beta_{F}$ $\left.=0^{\circ}\right)$.

During reverse operation, the QCSEE fan nozzle is in the flared position (Fig. 9 and 10 ) and sizeable openings exist between the four flaps and between the flaps and main nacelle in the hinge plane. Edges at the openings are relatively sharp. In an attempt to evaluate the effect of these openings on reverse performance, a fixed $30^{\circ}$ half-angle conic exlet having the same flap length and trailing edge sharpness wa: rabricated and tested. A schematic of the fixed $300^{\circ}$ exlet is shown in Fig. 11 and a photograph of it "on test" is shown in Fig. 12. Steadystate reverse testing reported herein included back-to-back tests with the fixed $30^{\circ}$ exlet and the movable flaps (QCSEE). All forward-toreverse transients were made with the movable flaps.

Since noise measurements were not of primary importance in these tests, the acoustic configuration used was the same as that tested immediately preceding this final test series. The acoustic configuration included the accelerating high Mach composite inlet with single-degreeof-freedom (SDOF) wall treatment, treated (bulk absorber) fan duct, and a multi phased stacked SDOF core suppressor. The acoustic fan duct splitter ring was removed. This configuration is described in detail in (4) and was designated as acoustic configuration 3 . 
INSTRUMENTATION - Because of the unique and rather complex nature of the QCSEE UTW engine, an abnormally large number of steady-state and transient pieces of information were obtained. Details of the instrumentation are presented in $(9,10)$, and only the pertinent instrumentation is discussed below:

1. Operational Safety Instrumentation - Pressures and/or temperatures in the lubrication and hydraulic system, cooling air supply, oil cooler, fuel system, bearings and seals, reduction gear and in high temperature regions were monitored.

2. Dynamic Instrumentation - Stress and vibration levels were continually monitored on selected fan blades, compressor inlet rakes, the slip ring strut, nozzle flap links, fan frame, fan OrV island, and on various locations on the fan doors. Vibration information was also continually gathered on all critical engine bearings, the accessory gear box, compressor case and the digital control. In an attempt to measure true engine thrust transient response, the two engine thrust links attaching the engine to the facility mounts were removed and replaced with special strain gaged links. Accelerometers located on the links and stand structure were used to compensate the strain signals for stand movement during the forward-to-reverse thrust transients with a resulting "true" thrust response.

3. Dynamic and Control Parameters - During the engine transient tests, four 8-channel brush-type recorders with selected information were used for "on-line" test monitoring and diagnostics. The parameters monitored are listed in Table 5.

4. Performance Instrumentation - Engine performance instrumentation is shown in Table 6 . In addition to the basic engine instrumentation, fan blade position, fan nozzle position, LP and HP rotor speeds were provided from engine control system sensors. Fuel flows were provided from the test cell system. Steady-state thrust readout was provided from a load cell with $25,0001 \mathrm{~b}$ forward thrust and $25,0001 \mathrm{~b}$ reverse thrust capability. The radial traverse probes (Sta 10 and 15) used \pm 10 psi range transducers. To avoid error due to flow angularity, the probe at the highlight (Sta 10) was aligned with the flow direction.

5. Acoustic - Noise measurements were not of primary importance during these tests, however, far-field noise was recorded during some of the reverse transients with a series of ground microphones spaced every $10^{\circ}$ from the inlet axis to $150^{\circ}$ on a $45.7 \mathrm{~m}$ ( $150 \mathrm{ft}$.) radius. Details of the noise acquisition and data reduction techniques are
discussed in ( 3$)$.

DATA REDUCTION - Steady-s tate reverse thrust performance tests included the direct measurement of the following parameters: engine thrust; fan blade angle; fan and core speeds; fan nozzle position (area); aft fan duct, core inlet, and inlet highlight total pressure radial profiles; fan and engine static pressures; ambient, aft fan duct, and 
core inlet air temperature; core engine total and static pressures and temperatures; and ambient conditions of wind velocity, temperature, pressure and relative humidity.

Steady-state reverse thrust data reduction equations are listed in Appendix B. The following parameters were calculated:

1. Corrected engine reverse thrust

2. Corrected fan and core speeds

3. Actual fan blade angle and fan nozzle area

4. Aft fan duct corrected airflow and Mach number

5. Exlet (aft fan duct) and core inlet total pressure recovery

6. Core compressor corrected airflow and pressure ratio, and estimated efficiency

7. Core engine corrected performance parameters

8. Fan airflow, static pressure ratios, and quasi total pressure ratio (at inlet highlight)

9. Exlet, engine, and fan inlet static pressure distributions

Forward-to-reverse thrust transient data reduction consisted of analyzing the data from four recorders (Table 5). Transient data was time synchronized by the power demand signal, and correlated with the steady-state data taken before and after each transient. Calculated values for each successful transient include actual overshoot blade angle, dwell time, actual blade travel time, blade pitch change rate, fan nozzle change rate; thrust response time, flow reattachment time, thrust delay after reattachment, and times to reach final fan speed and $f$ inal reverse static pressure ratio.

TEST PROCEDURE - Steady-state reverse tests of both the movable flap and the fixed $30^{\circ}$ exlets were performed in a similar fashion using the following general procedure:

1. Prior to start-up the desired fan blade angle and fan nozzle area for reverse idle, and other inputs were programmed into the engine digital control.

2. The engine was air motored using dry facility air. At about 3000 RPM core speed, the digital control received sufficient alternator current for regulation and the control signaled the fan blade and $f$ an nozzle to move to the preset reverse values. At about 4000 RPM core speed, the ignitors were activated and ignition was achieved. 
3. The engine was acoclerated to the reverse idle condition, about. $55 \%$ fan speed.

4. After the engine was warmed up for about ${ }_{i}$ min, conditions were adjusted to the desired settings for reverse data acquisition. Fan blind angle was normally set in the closed direction (sec Fig. 8).

Forward-to-reverse thrust transient testing was the last part of the test program because of the inherent greater $r$ isk to the engine compared to steady state testing. The sequence of the reverse transients was structured to increase in severity beginning with forward idle-to-reverse idle, and progressing to a forward takeof f-to-reverse thrust transient. Each transient consisted of the following steps:

1. Take forward thrust steady-state data

2. Initiate transient to a reverse set point (blade angle, fan speed and fan nozzle area)

3. Take reverse thrust steady-s tate data

4. Decrease speed to reverse idle

5. Initiate return transient to forward idle.

Al1 forward-to-reverse thrust transients included an automatic change in fan nozzle area from a forward thrust setting (convergent nozzle) to an open, approximately $30^{\circ}$ half-angle flared position to provide an inlet for reverse flow (exlet). Simultaneously, the fan blade pitch was changed on the order of $100^{\circ}$ from a forward thrust to reverse thrust setting. The transients were performed from nominal forward idle, approach and takeoff power to various levels of reverse thrust. other. variations included final reverse fan blade angle, blade angle overshoot, and fuel scheduling (fuel interlock setting) during the transient. The maximum attainable fan nozzle and fan blade pitch change rates were used in all the transients.

\section{STEADY -STATE REVERSE THRUST PERFORMANCE}

Reverse thrust performance was obtained with the engine at steadystate operating conditions. Covered in this section are reverse starting characteristics; overall, core engine, and fan performance; exlet and core inlet total pressure recovery; engine total pressure and temperature profiles; and the effect of the exlet configuration on steady-state reverse thrust performance. Operational boundary conditions were determined with relatively slow changes in either fan blade angle or fan speed.

REVERSE THRUST START ING CHARACTERISTICS - Because of the potential reverse "starting" problems (see Introduction), special attention was given to the initial reverse tests of the QCSEE UTW engine. All steady- 
state reverse startups were attempted with a preset reverse fan blade angle. Visual observations, as well as thrust readings, indicated reverse thrust was established at the onset of fan rotation for fan blade angles of $-91^{\circ},-96^{\circ}$ and $-103^{\circ}$. At a fan blade angle of $-86^{\circ}$, the fan appeared to be in a stalled, unstarted condition. The range of fan blade angles where reverse thrust maximizes, as will be discussed later, is $-93^{\circ}$ to $-97^{\circ}$. Consequently, there appears to be a margin of about $5^{\circ}$ in starting requirements, $\beta_{F}=-90^{\circ}$ for starting and $B F=-95^{\circ}$ for near maximum reverse thrust. Starting characteristics were similar for both the fixed $30^{\circ}$ exlet and the movable flap configuration.

OVERALL REVERSE THRUST PERFORMANCE - Variation of corrected reverse thrust with fan speed is shown in Fig. 13 for both the fixed $30^{\circ}$ exlet and movable flap configurations. At fan speeds up to $79 \%$ of design, thrust peaked at a fan blade angle of $-93.6^{\circ}$ for the fixed exlet; at higher speeds, and $\beta_{F}=-93.6^{\circ}$, turbine temperature limits were reached. As fan blade angle was held constant, reverse thrust increased almost linearly with increasing fan speed and began to level off above $80 \%$. Engine core limits were encountered at the higher reverse thrust levels for both exlet configurations. The $27,088 \mathrm{~N}(60901 \mathrm{~b})$ reverse thrust goal was attained with the fixed $30^{\circ}$ exlet while slightly exceeding the turbine temperature limit. At similar operating conditions and with the movable flap configuration installed, only about $22,240 \mathrm{~N}$ (5000 1b) reverse thrust was obtained.

Performance comparisons at constant fan speeds for the two exlet configurations are presented in Fig. 14. At the higher fan speeds, reverse thrust levels of about $26,700 \mathrm{~N}$ ( $60001 \mathrm{~b})$ were obtained at f'an blade angles between -93 and $-97^{\circ}$ with the fixed exlet (Fig. 14a). only small gains in reverse thrust with increases in fan speed above $81 \%$ are evident as seen by the collapsing speed lines. Maximum reverse thrust was limited by the boundaries indicated on the figure, namely, blade stress at low fan blade angles, core EGT limits near maximum reverse thrust blade angles, and fan speed limits at the higher "offloaded" blade angles. At the higher fan speeds, the sensitivity was about $890 \mathrm{~N}(200 \mathrm{lb})$ of reverse thrust per degree of fan blade angle for both configurations.

At $58 \%$ fan speed, a fan blade angle hysteresis check was made wi.th the fixed $30^{\circ}$ exlet (Fig. 14a). The data indicated less than $1{ }^{\circ}$ of hysteresis with blade angle at this speed. At blade angles from -83 to $-91^{\circ}$ significantly lower but measurable reverse thrust along with high blade stresses indicated the blades were in a partially stalled mode.

During these tests, consistently higher reverse thrust was obtained with the fixed $30^{\circ}$ exlet as compared to the movable flaps at all fan speeds and fan blade angles. In addition, lower blade-stresses, lower engine vibrations, and more stable reverse flow were observed. The reverse thrust objective of $27,088 \mathrm{~N}$ ( $60901 \mathrm{~b}$ ) could only be achieved with the fixed $30^{\circ}$ exlet configuration while slightly exceeding the turbine temperature limit. 
EXLET AND CORE INLET TOTAL PRESSURE AND TFMPERATURE CHARACTERISTICS During reverse operation, air enters the engine from the rear and exits through what is normally the engine inlet. The flow entering the core engine makes a $180^{\circ}$ turn and is divided into channels (Sta 21 to 25 , Fig. 6) by 6 equally spaced support struts. Rake data at the entrance to the core (Sta 25) were recorded during all steady-state readings.

Pressure and temperature profiles were measured during selected operating conditions at the entrance to the fan in reverse (Sta 15) at about a 10 $o^{\prime c l o c k}$ position and at the fan discharge (Sta 10) at a 6 o'clock position. The "V" shaped gaps between the four nozzle flaps (movable flaps) occur at about the $12,3,6$ and $90^{\prime}$ clock positions. Fan and core air flows were calculated from in-duct measurements and the procedures described in Appendix B.

As evidenced, exlet total pressure recovery was significantly improved with the fixed $30^{\circ}$ exlet over the movable flaps (Fig. 15). At an aft fan duct Mach number of 0.34 , the exlet total pressure recovery was .985 and .948 for the a forementioned configurations. Representative measured pressure and temperature profiles for the fixed and movable flap configurations at comparable fan speeds and fan blade angles are compared in Fig. 16. As can be seen, the pressure loss for the fixed exlet occurs near the outside wall compared to rather uniform losses across the entire duct for the movable flaps. A slight amount of exhaust gas reingestion was observed (Fig. 16a) with measured gas temperatures about $80 \mathrm{~K}$ $\left(15^{\circ} \mathrm{R}\right)$ above ambient near the inner wall. The traverse data at both the fan entrance and discharge was significantly more oscillatory in nature for the movable flaps indicating more flow turbulence. Static pressure distributions on the exlet surface (see Table 6) indicated flow separation on the inner surface from the sharp aft leading edge to over half the length of the exlet for both configurations. The increased pressure losses with the movable flaps are apparently caused by the sharp edge openings between the four flaps and between the flaps and the outer nacelle and pylon. Blockage or distortion also occurs due to the four flap hinges, actuator rods and pylon.

For the low pressure ratio QCSEE fan ( 1.08 in reverse), the exlet total pressure recovery is extremely important and, in this case, was the most significant factor causing the relatively low reverse thrust performance of the movable flap configuration.

The core inlet total pressure recovery did not reflect the significant differences observed in average exlet total pressure recovery. This is apparently a result of large pressure losses encountered in turning the flow $180^{\circ}$ at the gooseneck entrance to the core, and the fact that most of the core flow is scavenged from the lower recovery flow near the inner wall in the aft fan duct. Core inlet total pressure recovery was similar for both exlet configurations and decreased from about 0.94 to 0.80 as aft fan duct Mach number increased from 0.2 to 0.36. Compressor face pressure profiles at various circumferential locations are compared in Fig. 17. Both configurations had higher pressure recoveries near the inner wall in the core inlet, and in 
general, had similar profile shapes. Compressor face temperature profiles at the same conditions as the pressure profiles are shown in Fig. 18. The small amount of hot core gas reingestion measured at the inlet to the fan (Fig. 16) can also be observed at the compressor face. The variation of the average (area weighted) core inlet flow temperaturn rise with reverse thrust level for both configurations is shown in Fig. 19. At comparable reverse thrust levels, the amount of core exhaust gas reingestion into the compressor inlet appears to be several degrees more for the fixed exlet compared to the movable flap configuration.

CORE ENGINE PERFORMANCE IN REVERSE - Corrected core speed correlates well with corrected fan speed for a given fan blade angle, $\beta_{F}$, for both the fixed $30^{\circ}$ exlet and the movable flaps (Fig. 20). Core speed increases rapidly at constant. fan speed as fan blade angle is decreased (increasing reverse thrust). Calculated turbine power has similar characteristics. At high corrected core speeds, the core flow approaches a choking condition and remains relatively constant (Fig. 21). The increased turbine work requirement at higher core speeds results in a rapid rise in exhaust gas temperature as fuel is added (Fig. 22) with a notable change in slope at about $80 \%$ core speed. The core engine characteristics were similar for both configurations, although a slightly hotter engine exhaust gas temperature of $33^{\circ} \mathrm{K}\left(60^{\circ} \mathrm{R}\right)$ was required to operate at the same corrected core speed with the movable flap configuration.

Calculated specific fuel consumption minimized at a fan blade angle of about $-101^{\circ}$ for both configurations and was about 10 to $20 \%$ lower for the fixed exlet configuration.

FAN PERFORMANCE - Both the fixed and movable flap configurations had about the same calculated corrected flow-fan speed characteristics, Fig. 23. However, actual flows were significantly lower for the movable flap exlet reflecting the lower measured exlet total pressure recoveries (Fig. 6). Air flow was very sensitive to fan blade angle with f'low changes as high as $20 \%$ measured for $5^{\circ}$ blade angle changes near the fan design corrected speed. Fan performance measurements were limited to a total pressure and temperature radial traverse at the entrance to the fan, Sta 15 (Fig. 5) and at the fan discharge, Sta 10. The latter was taken 10. ? $\mathrm{cm}$ ( $4 \mathrm{in}$ ) forward of the inlet highlight. Static pressure measurements were also recorded at various stations in the fan flow passage.

Because the fan outlet traverse probe was located beyond the duct, a true total pressure ratio across the fan could not be measured. consequently, fan rotor tip static pressure ratio which is indicative of total pressure ratio, is presented as a function of corrected rotor flow in Fig. 24. The limited data indicate similar performance for both configurations. At lower rotor flows (lower fan speeds), the effect of blade angle is minimal with a tendency for the data to collapse on one operating line. At the higher flows, and corresponding higher fan speeds, separate operating lines exist as for a family of different fixed-pitch fans. Data obtained with a 20-inch diameter model (15) ir 
the QCSEE fan show reasonable agreement in the general trends. Typical pressure recovery data obtained with the downstream probe is compared for both configurations in Fig. 25. The fixed exlet configuration had a higher level of total pressure in the exhaust which was concentrated towards the outer wall and neither configuration had outward reverse flow in the center portion. Radial traverse data also indicated significantly more flow instability ahead of and behind the fan with the movable flap configuration; higher blade stresses and engine vibrations were also measured with this configuration. Static wall pressure distributions in the engine inlet (fan discharge) were similar for both exlet configurations.

Al though fan performance measurements were limited, it appears that the increased flow distortion and flow turbulence associated with the movable flap configuration, did not significantly affect the fan operating characteristics. These data strongly suggest that the higher thrust level of the fixed $30^{\circ}$ exlet is caused primarily by improved exlet total pressure recovery (see earlier discussion) and not by changes in fan performance.

A complete listing of all steady-state performance data acquired for both the fixed $30^{\circ}$ exlet and the movable flap configurations is presented in Appendices $C$ and $D$, respectively.

\section{FORWARD-TO-REVERSE THRUST TRANSIENT PERFORMANCE}

A primary requirement of the UTW engine system was the capability of a transient thrust reversal in less than $1.5 \mathrm{sec}$ from approach-to-reverse thrust. To accomplish this, the digital control, on command, synchronized fuel flow changes, fan blade pitch change and the flaring of the fan nozzle movable flaps. Transients were initiated from nominal forward idle, approach and takeof $f$ power to various levels of reverse thrust. Other variations included final reverse blade angle, blade angle overshoot, and fuel scheduling during the transient. A total of nineteen transients were made, all with the movable flaps.

DEFINITIONS OF TRANSIENT TERMS - Definitions and pictorial representation of the terms used in the forward-to-reverse transients are presented in Table 7 and Fig. 26, respectively. For these tests, the primary parameter of interest is the time from the demand for reverse until $80 \%$ of the final reverse thrust is achieved. This thrust response time is designated "RESP" . The digital control system was designed such that fuel flow was cut back to an idle setting at the beginning of each transient and held there until the fan blades were well into the transient. Blade position during the transient (fuel interlock setting) was used as the control switch to increase fuel flow. Since the blades reversed such that the angle increased in absolute magnitude $\left(e .8 ., 0^{\circ}\right.$, $\left.-1^{\circ},-2^{\circ} \cdot .-99^{\circ},-100^{\circ}\right)$ during each transient, lower fuel interlock settings $\left(-50^{\circ}\right)$ caused fuel to be increased sooner than higher settings $\left(-90^{\circ}\right)$. 
Besides the direct measurement of enfine thrust, two other measured parameters, fan blade stress and fan static pressure ratio, were indicative of establishing reverse thrust and are presented. As observed in previous tests (7), fan blade stresses increased substantially during a transient and then sudienly dropped when reverse thrust was established. Also, fan static pressure ratio became zero as the blades stalled, and changed sign as the flow reversed through the engine.

TRANSIENT PERFORMANCE - Summarized in Table 8 is the transient test program. Each transient began at a forward thrust set point $F_{X}$, automatically, on command, transitioned to a reverse set point $R_{x}$, then a decrease in speed to reverse idle $R_{1}$, and finally a transient to forward idle $F_{1}$. The nineteen transients are identified as to set point sequence planned $\left(F_{X}-R_{X}-R_{1}-F_{1}\right)$, programmed blade angle overshoot, and the fuel interlock setting angle. Blade angle overshoot was designed for a constant ten degrees beyond final set point for a nominal $0.3 \mathrm{sec}$ time duration. Approximate values of fan blade angle $\left(\beta_{F}\right)$, fan nozzle area $(A 18)$, and fan speed $\left(N_{F}\right)$, are tabulated for the three forward set points, $F_{1}, F_{2}$ and $F_{3}$, corresponding to nominal idle, approach and takeoff power settings, respectively. Similar values are listed for the nine reverse set points. Measured $\beta_{F}, N_{F}$ and Al 8 steady-state reverse values agreed with the scheduled digital control values. Final reverse thrust levels also compared well with previous steady-state thrust data. Transient $13 \mathrm{~A}$ was performed with an inadvertent control input for final blade angle of $-86^{\circ}$ rather than $-96^{\circ}$, and the engine did not establish reverse thrust because of fan blade stall. This transient is included to help define operational limitations.

After a few transients were performed, it became apparent that fan overspeed would not be a problem. The pre-test concerns of fan overspeed soon gave way to concerns of excessive fan speed decay or undershoot and subsequent long fan spool up times. Attempts to minimize or eliminate this problem were unsuccessful and are discussed later. As a result of this fan speed undershoot, some of the tests planned to investigate ways to minimize thrust response and flow reattachment times by systematic variations in blade pitch change rate and feedback sensitivity were eliminated.

Variation of selected measured parameters during an approach-toreverse thrust transient without and with fan blade overshoot are presented in Fig. 27 and 28, respectively. A takeoff-to-reverse transient is shown in Fig. 29. During all transients, the fan nozzle movable flaps and the fan blades were moved at their maximum rates. The nozzle flaps (Al8 trace) began movement without any measurable lag and moved smoothly and rapidly to the reverse position in 0.7 to 0.8 sec during all the transients. Fan blade movement typically began about 0.1 sec after transient initiation and also moved smoothly and rapidly to the reverse position. However, the blades momentarily overshot the final reverse blade angle by about $3^{\circ}$ but damped out to the programmed angle in several cycles. Similarly, 30 of momentary excess overshoot and cyclic 
damping occurred when overshoot was programmed (Fig. 28). For the approach and takeoff-to-reverse thrust transients, fan blade pitch change rates ranged from 107 to $120 \mathrm{deg} / \mathrm{sec}$.

The most unexpected transient characteristic observed was the excessive fan speed, $N_{F}$, decay or undershoot (Fig. 27 for example) which occurred during the initial portion of each transient. Fan speed dropped approximately $1200 \mathrm{RPM}$ in about $0.7 \mathrm{sec}$ before beginning to recover. The long fan spoolup times resulted in longer than expected times to establish full reverse thrust. Consequently, thrust response time was defined as the time to achieve $80 \%$ of final reverse thrust. As can be seen in a typical transient (Fig. 27), all the significant reverse elements (e.g., fan flow was reattached to the fan blades and the fan was not stalled) had been achieved by this time (RESP).

Engine thrust ( $F G$ ) time histories indicated a brief forward thrust surge of about $14680 \mathrm{~N}(3300 \mathrm{Ib})$ for $0.25 \mathrm{sec}$ and $2220 \mathrm{~N}(500 \mathrm{Ib})$ for 0.1 sec as fan blades initially moved open toward stall during the approach and takeoff-to-reverse transients, respectively (Fig. 28 and 29). Subsequently, thrust decayed to zero in about. $0.5 \mathrm{sec}$ as the blades rotated through stall. Reverse thrust was established in about $1.5 \mathrm{sec}$ and 1.6 sec for the approach-to-reverse thrust transients with and without overshoot, respectively (Fig. 28 and 27). The shortest thrust response time RESP of 1.1 sec was measured during the takeoff-to-reverse thrust transient (Fig. 29).

For the approach-to-reverse thrust transients, fan blade stress usually peaked after the blade reached the final reverse blade angle (Fig. 27). For the takeoff-to-reverse transient, fan blade stress peaked earlier at about a $\beta_{F}$ of $-50^{\circ}$ at which time the fan was stalled (Fig. 29). In some transients, e.g., Fig. 27, blade stress decrease was a good indicator of the establishment of reverse thrust, as was the case with the Hamilton-Standard Q-Fan demonstrator $(7,8)$. In other cases, e.g., Fig. 28, blade stress decrease did not correlate well with the establishment of reverse thrust.

Fan tip static pressure ratio, PS2/PS16, decreased slowly throughout the transient as the fan blade moved from forward to reverse blade angles, but lagged, to some degree, measured load cell thrust response times. Tip static pressure ratio could be used in a variable pitch fan engine flight configuration to determine initiation of reverse thrust.

Core speed, $\mathrm{N}_{C}$, characteristics were similar for all transients, decreasing initially, reaching a minimum in about $0.7 \mathrm{sec}$ and then increasing smoothly to a steady-s tate value.

The overall sound pressure level, OASPL, at $70^{\circ}$ from the inlet (maximum noise location during reverse) at a $46 \mathrm{~m}$ (150 ft) radius is shown in the lower curve of these figures. Peak noise levels occur after reverse thrust is established and appear to maximize when final fan speed is reached. Maximum OASPL in reverse is only about $1-2 \mathrm{~dB}$ higher than 
the maximum OASPL during forward takeoff thrust. However, the perceived noise during reverse is significantly more disturbing because of much higher noise levels in the 1500 to $6000 \mathrm{~Hz}$ high annoyance frequency range.

A typical return transient from reverse idle to forward idle is showr: in Fig. 30. Blade stresses reached maximum levels at about 0.5 sec into the return at about a $\beta_{F}=-70^{\circ}$. The relatively slow blade travel time of about 1.7 sec in the return direction, compared to about 1.0 sec normally, probably contributed to the relatively high stresses measured.

A summary of all measured and calculated transient performance parameters is tabulated in Appendix E. In Fig. 31 through 36, an attempt was made to isolate the effects of: 1) initial and final fan speed, 2) final blade angle, 3) blade angle overshoot, and 4) fuel scheduling, on thrust response characteristics. As discussed earlier, the fact that large unexpected fan speed decays and subsequent long fan spool up times were encountered during all transients made it difficult to interpret the effect of other parameters. The effect of initial fan speed on RESP and TNF is shown in Fig. 31. As might be expected, thrust response time is shortened when the transient is initiated at higher fan speeds during initial forward thrust operation. As previously discussed, the time to bring fan speed up to $98 \%$ of final value, TNF, is greater than RESP and decreases as the initial fan speed is increased.

The effect of final reverse fan speed is shown in Fig. 32 for transients beginning at low forward fan speeds $\left(N_{F K}=57 \%\right)$. Even though the fan blade pitch change rate was somewhat more rapid during transients to higher reverse fan speeds, the thrust response time was significantly longer due to longer fan spool up times. Final reverse fan speed level had a negligible effect on TNF, BT and RESP if the transient was initiated at high fan speeds, $\mathrm{N}_{\mathrm{FK}}=88 \%$ (Transient 12. vs 11). To minimize thrust response time, transients should be initiated from relatively high fan speeds in forward thrust and fan speed should be maintained during the transient.

The effect of final reverse fan blade angle on thrust response for transients beginning from approach power is shown in Fig. 33. Data from trans ient $13 \mathrm{~A}$ where the blades were in stall is shown for reference. At the same final fan speed, reverse thrust increases as blade angle decreases. Final blade angle had a negligible effect on thrust response time RFSP. Longer fan spool up times, TNF, are associated with the higher thrust, more loaded blades $\left(\beta_{F}=-100^{\circ}\right)$. The time until flow reattaches to the fan blades as determined by the decrease in blade stress (BT + RAT) also increases significantly as the fan blade angle is decreased (increasing reverse thrust).

A fixed $10^{\circ}$ blade angle overshoot of $0.3 \mathrm{sec}$ duration was designed into the control system as a possible solution to anticipated reverse flow starting problems. As discussed earlier, no reverse starting problems were encountered. As shown in Fig. 34 , the fixed blade angle overshoot was measured at $13^{\circ}$ and had a negligible effect on thrust. 
response time. However, the magnitude and duration of high alternating blade stress during the transients was signiricantly shortened when blade angle overshoot was used (Fig. 3.5).

The time at which fuel flow was increased after the initial cutback during each transient was controlled by the digital control fuel interlock setting (see Definitions of Transient Terms section). The effects of this parameter are shown in Fig. 36. Variations between -50 and $-90^{\circ}$ interlock settings did not enhance the unexpected fan speed decay (undershoot) problem as seen at the top of the figure. Neither were thrust response and blade travel times significantly affected. However, time to reach final fan speed, TNF, did appear to minimize at an angle of $-60^{\circ}$. Fan speed was near its minimum when the fan blades had rotated to about $-50^{\circ}$ during the reversals (see Fig. 27, 28 and 29). Increasing fuel flow sooner, (interlock settings less than -500) might have been beneficial but were not tested because of concerns about possible control system dynamic problems.

Initial design studies of the digital control system indicated possible problems of fan speed overshoot as the fan blades unloaded while changing pitch to the reverse position. To minimize fan overspeed, fuel cutback to flight idle at the onset of all forward-to-reverse transients was incorporated into the digital control logic. No fan overspeed problem was observed in these tests. Apparently the initial fuel cutback was either too abrupt or too severe as unexpected large fan speed decays occurred during the initial portion of the transients and resulted in subsequent long fan spool up times. Within the range tested, rescheduling the time to introduce fuel flow earlier after the initial fuel cutback was unsuccessful in reducing the amount of fan speed decay or length of time to reach final fan speed. No attempt was made to modify the control system logic for these tests. To reduce the time to reach final fan speed in future tests the digital control logic could be modified by controlling fan speed during the transient, delaying slightly the initial fuel cutback, cutting back fuel at a slower rate, or cutting back to a higher fuel flow level above flight idle.

\section{SUMMARY}

Steady-state reverse and forward-to-reverse thrust transient performance were obtained with the QCSEE. UTW geared variable pitch turbofan engine at the NASA Lewis Research Center. The UTW engine fell short of its reverse thrust goal during its initial testing at the Contractor's facility. It was retested in reverse in its original configuration and with a modified exlet which significantly improved performance. The engine met the steady-state reverse thrust and transient thrust reversal goals. The digital electronic control, variable pitch actuation system, variable pitch composite fan blades and variable fan nozzle operated satisfactorily throughout the tests.

STEADY-STATE REVERSE RESULTS - Reverse thrust performance was obtained with two fan nozzle (exlet) configurations: (a) the QCSEE 
4-segment variable area fan nozzle with openings in the flap hinge area and between the flaps when in the reverse position (movable flaps); and (b) a boilerplate continuous, non-gap, $30^{\circ}$ half-angle conical exlet (fixed $30^{\circ}$ exlet). The steady-s tate results are summarized below:

1. The reverse thrust goal of $35 \%$ of forward static takeof $f$ thrust was attained with the fixed $30^{\circ}$ exlet. Reverse thrust with the movable flaps was about $20 \%$ less. In order to retain the variable area capability in a flight design and utilize the improved performance concept of the fixed $30^{\circ}$ exlet, a new improved movable flap design is required.

2. Lower engine vibrations, lower fan blade stress and more stable flow occurred with the fixed $30^{\circ}$ exlet as compared to the movable flaps.

3. No reverse starting problems existed for either configuration.

4. The reverse thrust goal was obtained in a fan blade angle range of about 40 . The operating envelope was bounded by fan blade stress, core exhaust gas temperature, and fan speed limits.

5. Fan performance characteristics did not appear affected by exlet geometry; improved reverse thrust with the fixed $30^{\circ}$ exlet appeared to be a direct result of improved exlet total pressure recovery.

6. The core engine characteristics were similar for both configurations, although a slightly hotter engine exhaust gas temperature of about $33^{\circ} \mathrm{K}\left(60^{\circ} \mathrm{R}\right)$, was required to operate at the same corrected core speed with the movable flap configuration. Core engine limits were encountered at the high thrust levels with both configurations.

7. Specific fuel consumption was about 10 to $20 \%$ lower for the fixed $30^{\circ}$ exlet and optimized at a fan blade angle of about $-101^{\circ}$ for both configurations.

TRANSIENT RESULTS - Forward-to-reverse thrust transient performance was obtained with the movable flaps only. Automatic thrust reversals were coordinated by the digital control, which on command, synchronized fuel flow changes, fan blade pitch change and the flaring of the fan nozzle movable flaps. Results from the 19 forward-to-reverse thrust transients are summarized below:

1. The transient thrust reversal goal of 1.5 sec from approach-toreverse thrust was achieved. The takeoff-to-reverse thrust transient was performed in $1.1 \mathrm{sec}$.

2. Unexpected large fan speed decays and subsequent long fan spool up times were encountered during all transients, apparently due to the early fuel cutback to flight idle as the transient was initiated. To alleviate this problem, the digital control logic could be modified by controlling fan speed during the transient, delaying the initial fuel 
cuthack, cutting back fuel al a :slower rate, or culting bick fuel to a higher level above flight idle.

3. Fan blade pitch change typically began about, $0 . L$ sec after transient initiation, moved smoothly, and inomentarily overshot the final reverse blade angle by about $3^{\circ}$, but damped out to the programmed angle in several cycles. Fan blade travel times were on the order of 1.0 sec with measured average pitch change rates from 107 to $120^{\circ} / \mathrm{sec}$.

4. Programmed fan blade angle overshoot $\left(10^{\circ}\right.$ for $\left.0.3 \mathrm{sec}\right)$ did not affect thrust response times significantly, but did reduce the magnitude and duration of high blade stress.

5. Fan exhaust nozzle (movable flaps) opened rapidly and smoothly to the reverse setting in about 0.7 to $0.8 \mathrm{sec}$.

6. A very brief forward thrust surge of $14680 \mathrm{~N}$ ( $3300 \mathrm{Ib}$ ) and 2220 $\mathrm{N}(500 \mathrm{lb})$ occurred as the fan blades initially moved open toward stall during the approach and takeoff-to-reverse transients, respectively.

7. No problems were encountered in establishing reverse thrust, although it took longer times at the higher thrust, more loaded blade angles.

8. Maximum overall sound pressure level was about $1-2 \mathrm{db}$ higher in reverse than at takeoff. However, no anomolies were encountered during
the transients. 
REFERENCES

1. W. S. Willis; "Ouict Cinan Short-llul Fxperimental Fngine (QCSEE)," Genera l Flectrie (o., Cineinnati, OH, Report. No. 1779AFGli78, August, 1979. (NASA CR 1501173, 1979)

2. "Quiet, Powered-Lif't Propulsion Conference," NASA 2077, 1978.

3. I. J. Loeffler, N. E. Samanich, and H.E. Bloomer "OCSEE UTW Engine Powered-Lift Acoustic Performance," AIAA-80-1065, June, 1980.

4. H. E. BIoomer, and N. E. Samanich "OCSEE Fan Exhaust Bulk Absorber Treatment Evaluation," AIAA-80-0987, June, 1980.

5. R. E. Neitzel, R. Lee, and A. J. Chamay "QCSEE Task 2: Engine Installation Preliminary Design," General Electric Co., Cincinnati, OH, June, 1973. (NASA CR-134738, 1973)

6. H. E. Helms "Quiet Clean STOL Experimental Engine Study Program. Task I: Parametric Propulsion Systems Studies," Detroit Diesel Allison, Indianapolis, IN, Report No. EDR-7543, September, 1972. (NASA CR-135015, 1972)

7. J. W. Schaefer, D. A. Sagerser and E. G. Stakolich "Dynamics of High-Bypass-Engine Thrust Reversal Using a Variable-Pitch Fan," NASA TM $\mathrm{X}-3524,1977$.

8. D. C. Reemsnyder and D. A. Sagerser "Ef fect of Forward Velocity and Crosswind on the Reverse-Thrust Performance of a Variable-Pitch Fan Engine," AIAA Paper No. 79-0105, January, 1979.

9. "Quiet Clean Short-Haul Experimental Engine (QCSEE) - Under the Wing (UTW) Engine Boilerplate Nacelle Test Report, Volume 1: Summary Report," General Electric Co., Cincinnati, OH, Report No. R77AEG2121 VOL 1, December, 1977. (NASA CR-135249, 1977)

10. "Quiet Clean Short-Haul Experimental Engine (QCSEE) - Under the Wing (UTW) Engine Composite Nacelle Test Report, Volume 1: Summary, Aerodynamic and Mechanical Performance," General Electric Co., Cincinnati, OH, Report No. R78AEG573 - VOL 1, April, 1979. (NASA CR-159471, 1979)

11. W. F. Vier "Quiet Clean Short-Haul Experimental Engine (QCSEE) Test Results from a $14 \mathrm{~cm}$ Inlet for a Variable Pitch Fan Thrust Reverser," General Electric Co., Cincinnati, OH, Report No. R75AEG387, December, 1975. (NASA CR-134867, 1975)

12. D. A. Dietrich, T. G. Keith and G. G. Kelm "Aerodynamic Performance of Flared Fan Nozzles Used as Inlets," NASA TM X-3367, 1976. 
13. "Quiet Clean Short-Haul Experimental Engine (OCSEE) - Under the Wing (UTW)," General Electric Co., Cincinnati, OH, Final Design Report, June, 1977. (NASA CR-134847, 1977)

14. "Quiet Clean Short-Haul Experimental Engine (QCSEE) - Under the Wing Engine Digital Control System Design Report," General Electric Co., Cincinnati, OH, Report No. R75AEG483, January, 1978. (NASA CR-134920,
1978)

15. R. G. Giffen, R. A. MCFalls and B. F. Beacher "QCSEE Aerodynamic and Aeromechanical Performance of a $50.8 \mathrm{~cm}$ (20 in) Diameter, $1.34 \mathrm{PR}$ Variable Pitch Fan with Core Flow," General Electric Co., Cincinnati, OH, Report No. R75AEG445, August, 1977. (NASA CR 135017, 1977) 
TABLE 1.- QCSEE UTW TECHNICAL GOALS (FOUR-ENGINE, 400,320-N (90,000-1W) THRUST AIRCRAFT)

Goals

Noise - $152 \mathrm{~m}(500 \mathrm{ft})$ sideline

Approach, EPNdB

95

Takeoff, EPNdB

Reverse, PNdB

95 EPNdB Contour Area, sq km (sq mile)

95

100

Pollution

$1.29(0.5)$

EPA 1979 Emission Levels

Installed Thrust

Forward, $N(1 b)$

Reverse ( $\%$ of takeoff thrust)

$77395(17400)$

35

Specific Fuel Consumption, g/sec-kN (1b/hr-lb)

$9.6(0.34)$

Installed Thrust/weight

4.3

Thrust Response

Approach to Takeoff, sec

Approach to Reverse, sec

1.0

1.5

TABLE 2 - AERODYNAMIC DESIGN PARAMETERS

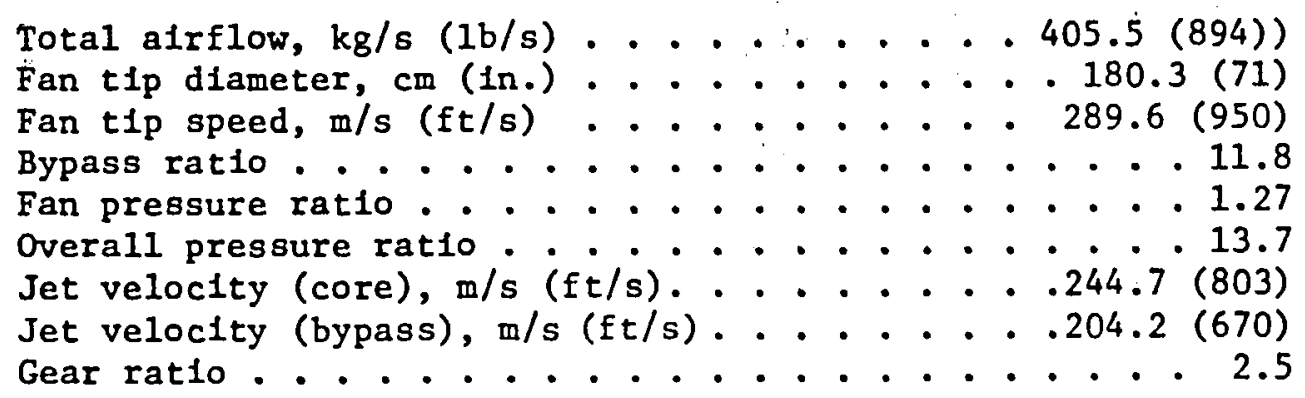


TALE 3 - MCOUSTIC DESIGR PAMARTER

[41.2 m/sec (BO bnots) alrcraft epeed; 61 m (200 ft) altitude; takenff conditlons.]

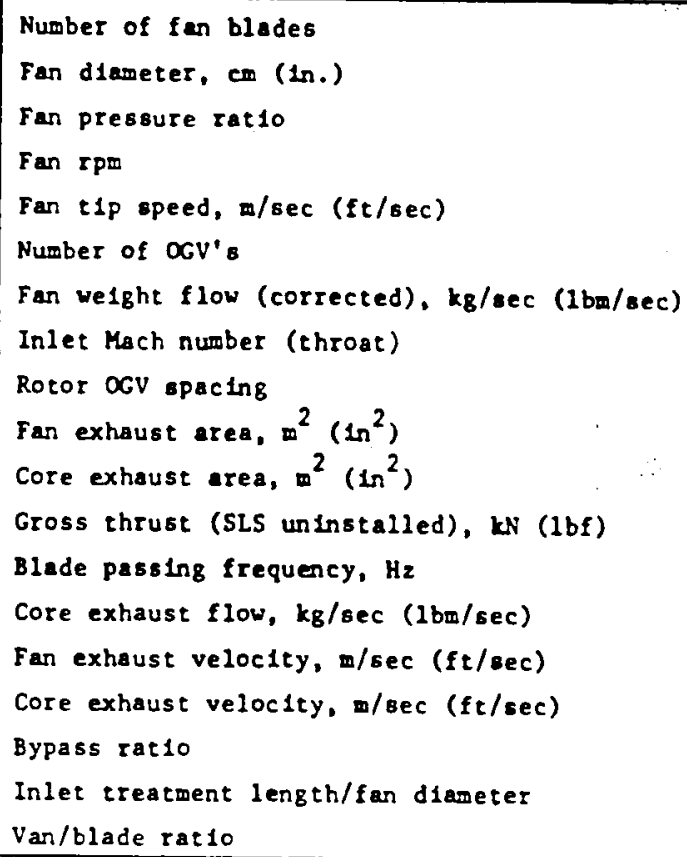

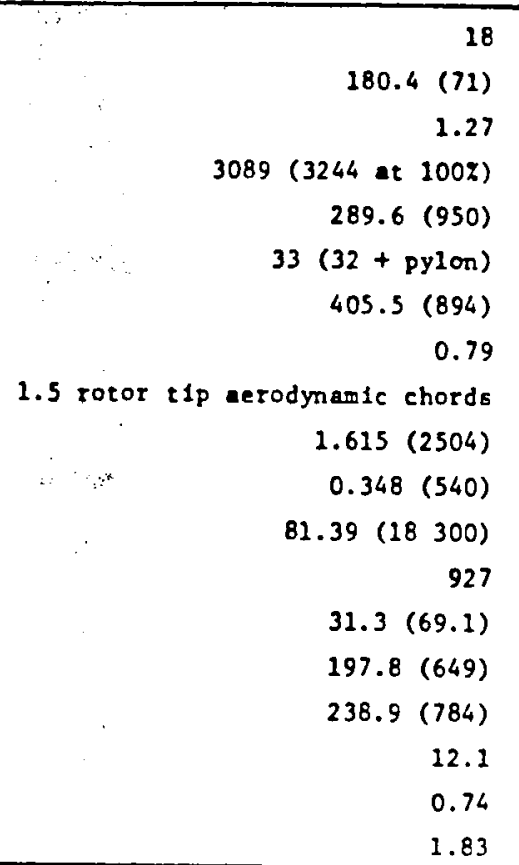

TABLE 4 - QCSEE UTW PERFORMANCE

(PREVIOUSLY REPORTED)

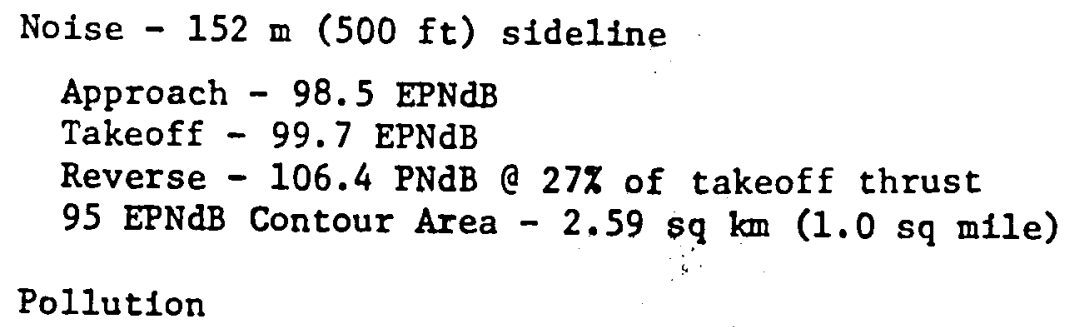


Ch. No.

$\star 1$
2
3
4
5
6
7
8

$$
\begin{array}{r}
* 7 \\
2 \\
3 \\
4 \\
5 \\
6 \\
7 \\
8
\end{array}
$$

\section{Parameter}

SANBORN A

Power Demand (PD) or Mode

A18 TMC

Nozzle Area, A18

Core Speed N2

Fan Speed NIF

Thrust, FG (load cell)

Calc T47, T4lC

Pressure Ratio, PS3/pto

\section{SANBORN B}

\section{Power Demand or Mode}

WF TMC (fuel flow - torque motor current)

WF (fuel flow)

FMP (fuel manifold press)

XMI1 (throat Mach No.)

PLA (power lever angle)

VSV (variable stator vane)

Selectable Channel

\section{SANBORN C}

Power Demand or Mode

Bf TMC

Fan Pitch Angle, $B f$

Bf open pressure

Bf close pressure

Blade Strain

Blade Strain

Blade Strain

\section{SANBORN D}

Thrust FG (load cell)

Link 1 Strain

Link 2 Strain

Link Accel erometer

Load Cel1 Accelerometer

Link AVG Compensated

Load Cell Compensated

True Thrust Transient *Power Demand (PD) for Forward Transients and (Mode) for
Reverse Transients 
TABLE 6 - engINE PERfORMANCE INSTRUMENTATION

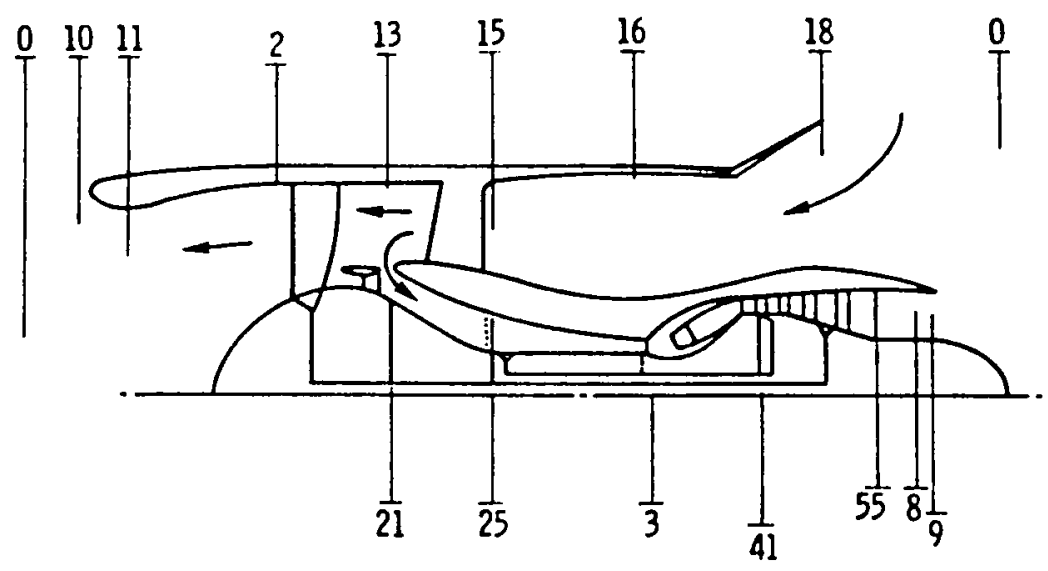

Inlet Highlight (Sta 10)

$P t$ and $T$ t radial traverse $180^{\circ}$

QCSEE Inlet (Highlight to compressor face)

2 axial rows of 16 wall statics $180^{\circ}$ and $270^{\circ}$

1 circumferential row of 8 wall statics at throat (5ta 11 )

Fan Frame (- Sta 13)

19 statics on outer wall

Bypass Duct Fan Inlet (Sta 15)

$\mathrm{Pt}$ and $\mathrm{Tt}$ radial traverse $283^{\circ}$

Fan Duct Measuring Station (Sta 16)

4 outer wall and 4 inner wall statics

Fan Duct Entrance

2 statics on outer wall

$30^{\circ}$ Exlet

I axial row of 9 wall statics

Movable Flaps

4 axial rows of 7 wall statics each of flap $\# 3$

Core Entrance Island (- Sta 21 )

5 island wall statics

5 core $06 \mathrm{~V}$ vane statics

2 hub wall statics

2 3-element $P t$ rakes $170^{\circ}$ and $350^{\circ}$

Core Entrance Splitter L1p (- Sta 21)

4 wall statics

Core Entrance Gooseneck (Sta 21 to 25)

6 inner wall statics

Compressor Face (Sta 25)

4 outer and 4 inner wall statics

6 5-element pt rakes $16,82,105,145,225,282^{\circ}$

6 5-element tt rakes $16,82,105,145,225,282^{\circ}$

Core Compressor Discharge (Sta 3 )

$\begin{array}{ll}1 & \text { T3 probe } \\ 1 & \text { PS3 } 3 \text { probe }\end{array}$

LP Turbine Frame Discharge (Sta 55)

1 5-element to rake 
TABLE 7 - FORWARD-TO-REVERSE THRUST TRANSIENT TERMS

BT

Blade travel time, s; time from request to reverse engine thrust until fan blade initially reaches within $1^{\circ}$ of overshoot blade
angle

DELAY Thrust delay after reattachment, $s$; time from flow reattachment to fan blade (blade stresses drop below reference value) until $80 \%$ of final reverse thrust is achieved.

DOV Number of degrees of overshoot beyond the final reverse blade angle, deg.

DWELL Time that fan blade is held at the overshoot blade angle, $s$.

NFOS Max fan speed above reverse set point, RPM

NFUS Min fan speed blow forward set point, RPM

OBA Overshoot blade angle, deg.

PCR Pitch change rate; average blade travel rate, $\frac{O B A-B_{F i}}{\text {, deg/s }}$

PD Power demand, \%

RAT Flow reattachment time, $s$; time when fan blade intially reaches within $1^{\circ}$ of overshoot blade angle until fan comes out of stall (blade stresses drop below reference value)

RESP Thrust response time, $s$; the from request to reverse engine thrust until $80 \%$ of final reverse thrust is achieved (RESP $=\mathrm{BT}$ + RAT + DELAY)

TA18 Time from request to reverse engine thrust until Al8 opens to $98 \%$ reverse setting

TNF Time from request to reverse engine thrust $98 \%$ of final fan speed is achieved, s.

TSP Time from request to reverse engine thrust until $98 \%$ of final reverse static pressure ratio PS2/PS16 is obtalned, s. 
TABLE 8 - SUMMARY OF FORWARD-TO-REVERSE TRANSIENTS

\begin{tabular}{|c|c|c|c|}
\hline Number & Transient & $\begin{array}{c}\text { Blade } \\
\text { Overshoot } \\
\end{array}$ & $\begin{array}{c}\text { Fuel } \\
\text { Interlock } \\
\text { Setting } \\
\end{array}$ \\
\hline 1 & $F I-R I-F I$ & No & $-90^{\circ}$ \\
\hline 2 & $\mathrm{Fl}-\mathrm{Rl}-\mathrm{Fl}$ & No & $-90^{\circ}$ \\
\hline 3 & $\mathrm{Fl}-\mathrm{R} 2-\mathrm{R} 1-\mathrm{Fl}$ & No & $-90^{\circ}$ \\
\hline 4 & $F]-R 3-R]-F 1$ & No & $-90^{\circ}$ \\
\hline 5 & $F 1-R 4-R 1-F l$ & No & $-90^{\circ}$ \\
\hline 6 & $F 2-R 4-R 1-F 1$ & No & $-90^{\circ}$ \\
\hline 7 & $F 2-R 4-R 1-F 1$ & No & $-70^{\circ}$ \\
\hline 8 & $\mathrm{~F} 2-\mathrm{R} 4-\mathrm{R} 1-\mathrm{F} 1$ & No & $-60^{\circ}$ \\
\hline 9 & $\mathrm{~F} 2-\mathrm{R} 4-\mathrm{R} 1-\mathrm{Fl}$ & Yes $115 / 105$ & $-70^{\circ}$ \\
\hline 10 & $F 2-R 5-R]-F 1$ & No & $-70^{\circ}$ \\
\hline 11 & $\mathrm{~F} 2-\mathrm{R} 6-\mathrm{R} 1-\mathrm{F} 1$ & No & $-70^{0}$ \\
\hline 12 & $\mathrm{~F} 2-\mathrm{R} 7-\mathrm{R} 1-\mathrm{F}]$ & No & $-70^{\circ}$ \\
\hline 13 & $F 3-R 4-R 1-F 1$ & No & $-70^{\circ}$ \\
\hline 14 & $F 2-R 8-R 1-F 1$ & Yes $110 / 100$ & $-70^{\circ}$ \\
\hline 15 & $F 2-R 8-R 1-F 1$ & No & $-70^{\circ}$ \\
\hline 16 & $F 2-R 4-R 1-F 1$ & No & $-50^{\circ}$ \\
\hline $\begin{array}{r}17 \\
+10\end{array}$ & $F 2-R 4-R 1-F 1$ & Yes $115 / 105$ & $-50^{\circ}$ \\
\hline $\begin{array}{r}\star 18 \\
\star \quad 73 A\end{array}$ & $F 2-R 4-R 1-F 1$ & Yes $115 / 105$ & $-50^{\circ}$ \\
\hline$* 73 A$ & $F 2-R 9-R T-F 1$ & Yes $100 / 90$ & $-70^{\circ}$ \\
\hline
\end{tabular}

\begin{tabular}{|c|c|c|c|}
\hline \multicolumn{4}{|c|}{ Forward Set Points } \\
\hline & $\begin{array}{c}\beta \\
\text { (Panel) }\end{array}$ & $\begin{array}{c}\text { Al8 } \\
\text { (Panel) }\end{array}$ & $\begin{aligned} \sim & \text { Fan Speed } \\
& \operatorname{rpm}(\%)\end{aligned}$ \\
\hline \multirow[t]{3}{*}{$\begin{array}{l}F 1 \\
\text { F2 } \\
\text { F3 }\end{array}$} & $\begin{array}{l}+\quad 2.4 \\
0 \\
-10.0^{0}\end{array}$ & $\begin{array}{l}2480 \\
2900 \\
2350\end{array}$ & $\begin{array}{l}1800(56) \\
2850(88) \\
3073(95)\end{array}$ \\
\hline & Rev & e Set Po & \\
\hline & $\begin{array}{c}\beta \\
\text { (Panel) } \\
\end{array}$ & $\begin{array}{c}\text { Al8 } \\
\text { (Panel) }\end{array}$ & $\begin{array}{l}\sim \text { Fan Speed } \\
\text { rpm }(\%)\end{array}$ \\
\hline $\begin{array}{l}\text { R1 } \\
\text { R2 } \\
\text { R3 } \\
\text { R4 } \\
\text { R5 } \\
\text { R6 } \\
\text { R7 } \\
\text { R8 } \\
\text { R9 }\end{array}$ & $\begin{array}{l}-105 \\
-105 \\
-105 \\
-105 \\
-115 \\
-110 \\
-110 \\
-100 \\
-90\end{array}$ & $\begin{array}{l}3900 \\
3900 \\
3900 \\
3900 \\
3900 \\
3900 \\
3900 \\
3900 \\
3900\end{array}$ & $\begin{array}{ll}1806 & (56) \\
2083 & (64) \\
2637 & (81) \\
2894 & (89) \\
2890 & (89) \\
1800 & (56) \\
2886 & (89) \\
2624 & (81) \\
2624 & (81)\end{array}$ \\
\hline
\end{tabular}

*Blades stopped at $-57^{\circ}$. Lost hydraulic pressure. First fully automatic transient.

**Blades stalled. 
APPENDIX A

Symbols

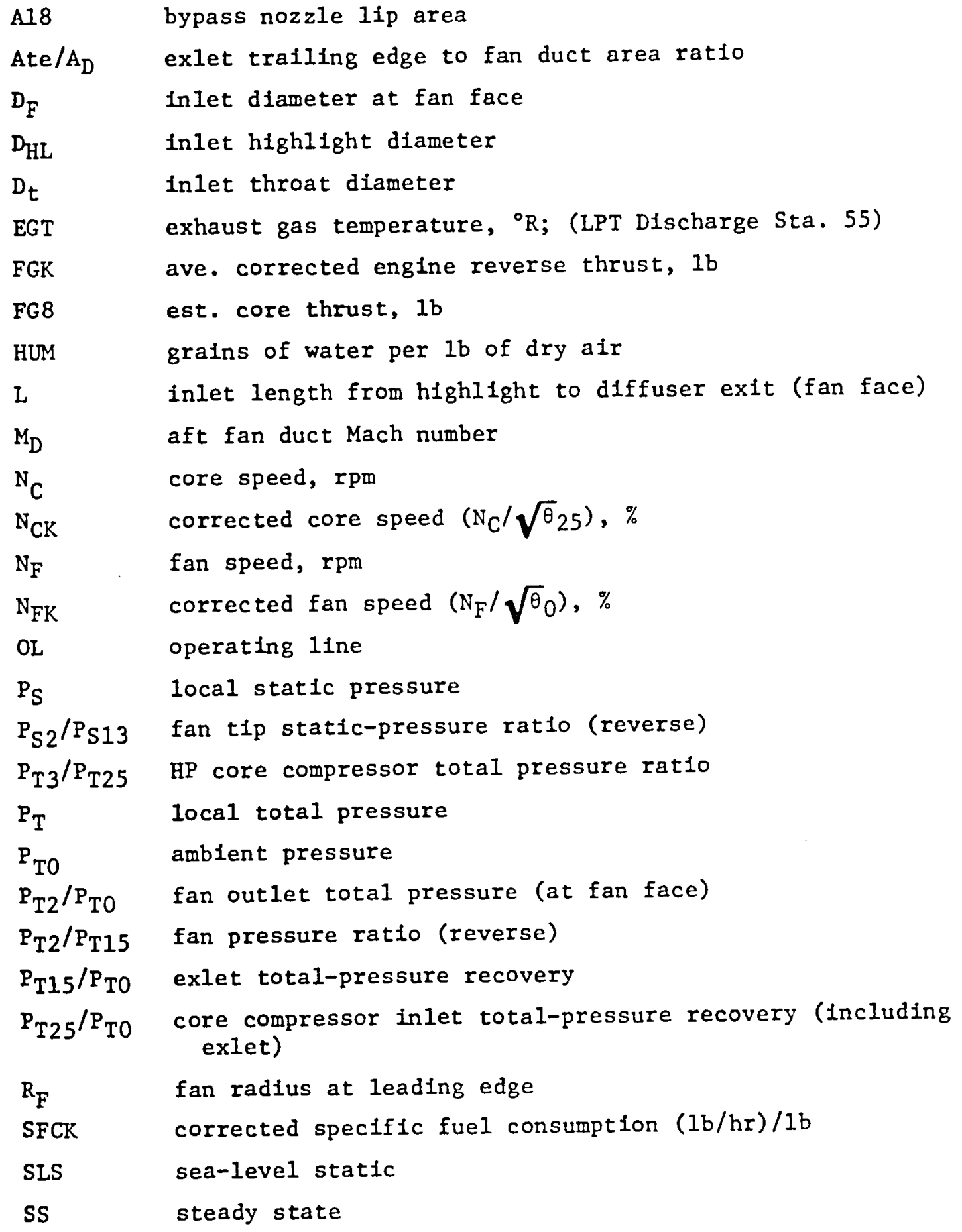




$\begin{array}{ll}\text { T0 } & \text { takeoff } \\ \mathrm{T}_{0} & \text { ambient temperature, }{ }^{\circ} \mathrm{R} \\ \mathrm{T} 25 & \text { core compressor inlet total temp., }{ }^{\circ} \mathrm{R} \\ \mathrm{T} 41 \mathrm{~K} & \begin{array}{c}\text { corrected } \mathrm{HPT} \text { rotor inlet total temperature, }{ }^{\circ} \mathrm{R} \text { (T3, PS3, } \\ \mathrm{W}_{\mathrm{F}} \mathrm{d} \text { digital control) }\end{array} \\ \mathrm{T} 55 \mathrm{~K} & \text { corrected exhaust gas temperature, }{ }^{\circ} \mathrm{R} \\ \mathrm{W} 11 \mathrm{~K} & \text { corrected fan rotor flow, } 1 \mathrm{~b} / \mathrm{s} \\ \mathrm{W} 15 \mathrm{~K} & \text { corrected aft fan duct flow, } 1 \mathrm{~b} / \mathrm{s} ; \text { (total fan plus core } \\ & \text { inlet flow) } \\ \mathrm{W} 25 \mathrm{~K} & \text { corrected core compressor } 1 \mathrm{nlet} \mathrm{flow}, \mathrm{lb} / \mathrm{s} \\ \mathrm{x} & \text { axial distance from inlet highlight } \\ \mathrm{B}_{\mathrm{F}} & \text { fan blade angle, angle from design forward blade angle, deg } \\ \delta & \text { ratio of total pressure to standard sea-level pressure } \\ \theta & \text { ratio of total temperature to standard sea-level temperature }\end{array}$




\section{APPENDIX B}

\section{Steady-State Reverse Thrust Calculations}

1. Corrected thrust, FGK

$$
F G K=\frac{F_{G}}{\delta 0}
$$

2. Weight flow

$$
W=2.0519 \times C_{D} \times A \times \frac{P_{T}}{\sqrt{T_{T}}} \times \sqrt{\left(\frac{P_{S}}{P_{T}}\right)^{1.427-\left(\frac{P_{S}}{P_{T}}\right)^{1.7135}}}
$$

For Aft Fan Duct Flow, $W_{15}$

$$
\begin{aligned}
& C_{D}=0.98 \\
& A_{16}=3262.8 \mathrm{in}^{2} \\
& P_{T}=P_{T 15}, \text { psia } \\
& T_{T}=T_{0}{ }^{O_{R}} \\
& P_{S}=P_{S 16}, \text { psia }
\end{aligned}
$$

For Core Flow, $W_{25}$

$$
\begin{aligned}
& C_{D}=0.70 \\
& A_{25}=328.68 \mathrm{in}^{2} \\
& P_{T}=P_{T 25}, \text { psia } \\
& T_{T}=T_{25}, \quad{ }_{R} \\
& P_{S 25}=\text { psia }
\end{aligned}
$$

For Rotor Flow, $W_{11}=W_{15}-W_{25}$

3. Corrected weight flow

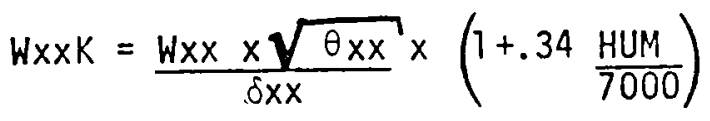

4. Aft fan duct Mach number, MD

$$
M_{D}=2.2319 \times\left[{\frac{P_{S}}{P_{T}}}^{-.2865}-1.0\right]^{\frac{2}{2}}
$$


5. Core compressor ${ }_{\text {p }}$ eessure ratio, $\mathrm{P}_{\mathrm{T} 3} / \mathrm{P}_{\mathrm{T} 25}$

$$
\frac{\mathrm{P}_{\mathrm{T} 3}}{\mathrm{P}_{\mathrm{T} 25}}=\frac{1.0193 \mathrm{P}_{\mathrm{S} 3}-2.05}{\mathrm{P}_{\mathrm{T} 25}}
$$

6. Corrected fan speed, $\mathrm{N}_{\mathrm{FK}}$

$$
N_{F K}=\frac{N_{F}\left(1-.26 \frac{\text { Hum }}{7000}\right) \times 100}{32.44 .1 \times \sqrt{\theta_{15}}}
$$

7. Corrected core speed, $N_{C K}$

$$
N_{C K}=\frac{N_{C}\left(1-.26 \frac{\text { Hum }}{7000}\right) \times 100}{N_{\text {CDES }} \times \sqrt{\theta_{25}}}
$$


APPENDIX C - STEADY-STATE REVERSE PERFORMANCE $30^{\circ}$ HALF-ANGLE CONICAL EXLET

\begin{tabular}{|c|c|c|c|c|c|c|c|c|c|c|c|c|c|c|c|c|}
\hline \multirow[b]{2}{*}{$R d g}$. & \multirow[b]{2}{*}{ deg. } & \multirow[b]{2}{*}{$\begin{array}{c}\mathrm{NFK} \\
6\end{array}$} & \multicolumn{2}{|c|}{$E N G \perp N E$} & \multirow[b]{2}{*}{$\begin{array}{l}\text { FGK } \\
\text { Ibs }\end{array}$} & \multirow[b]{2}{*}{$\begin{array}{l}T 41 \mathrm{~K} \\
\% \text { des, }\end{array}$} & \multirow[b]{2}{*}{$\begin{array}{l}\text { T55K } \\
x \text { des. }\end{array}$} & $O R E$ & \multirow[b]{2}{*}{$\begin{array}{c}\text { PT25 } \\
-.\end{array}$} & \multirow[b]{2}{*}{$\begin{array}{l}\text { N25K } \\
z \text { des, }\end{array}$} & \multicolumn{3}{|c|}{$F_{E} A_{X} L^{D_{E} U} T^{-T}$} & \multicolumn{2}{|c|}{$F A N N R E I$} & \multirow{2}{*}{$\underset{\mathrm{PS2}}{\stackrel{\mathrm{PSO}}{\longrightarrow}}$} \\
\hline & & & $\begin{array}{l}\text { NFK } \\
\text { rpm }\end{array}$ & $\begin{array}{c}\text { NCK } \\
:\end{array}$ & & & & $\underset{\text { PT25 }}{\text { PT3 }}$ & & & $\begin{array}{l}\text { MO } \\
-.\end{array}$ & PTI5/PTO & $\begin{array}{l}15 \mathrm{~K} \\
\mathrm{ibs} / \mathrm{s}\end{array}$ & $\begin{array}{l}\operatorname{Milk}_{1 \mathrm{bs} / \mathrm{s}} \\
\text { M }\end{array}$ & $\begin{array}{c}\text { PS2 } \\
\text { PS13 } \\
--\end{array}$ & \\
\hline 1011 & $-106,3$ & 61.2 & 1982 & 76,2 & -2264 & 66.3 & 75.3 & 5.50 & .934 & 51.1 & .198 & .994 & 367.6 & 336.4 & 1.043 & .981 \\
\hline 1013 & -106.2 & 82.7 & 2681 & 82.4 & -3687 & 75.4 & 81.2 & 8.22 & .897 & 72.9 & 258 & .992 & 470.3 & 427.5 & 1.075 & 967 \\
\hline 1014 & .106 .2 & 95.3 & 3088 & 84.9 & -4065 & 82.7 & 85.6 & 9.70 & 877. & 81.1 & .274 & . 990 & 497.5 & 450.8 & 1.085 & .955 \\
\hline 1018 & -101.2 & 59.3 & 1921 & 78.9 & -3038 & 68.1 & 75.5 & 6.41 & .912 & 60.0 & .228 & .992 & 419.0 & 383,2 & 1,056 & .978 \\
\hline 1020 & -101.2 & 82.2 & 2664 & 85.9 & -5213 & 84.1 & 88.6 & 10,28 & .843 & 86.8 & .313 & .989 & 560.0 & 512.4 & 1.125 & .962 \\
\hline 1021 & $=101.2$ & 88.3 & 2863 & 87.4 & .5400 & 88.6 & 93.1 & 11.10 & .833 & 90.5 & .320 & .988 & 571.2 & 521.6 & 1.139 & .954 \\
\hline 1030 & -101.2 & 56.8 & 1845 & 78.4 & -2796 & 67.8 & 75.1 & 6.17 & .914 & & & & & & 1.058 & .981 \\
\hline 1031 & -101.2 & 64.1 & 2079 & 80.8 & -3440 & 71.4 & 78.1 & 7.25 & .895 & & & & & & 1.074 & .974 \\
\hline 1032 & -101.2 & 82.2 & 2667 & 86.0 & -5150 & 84.8 & 89.4 & 10.28 & .841 & 86.9 & & & & & 1.125 & .961 \\
\hline 1033 & -101.2 & 88.1 & 2856 & 87.4 & -5375 & 89.1 & 93.4 & 11.10 & .832 & 91.4 & & & & & 1.142 & 956 \\
\hline 1034 & -101.3 & 95.1 & 3085 & 88.5 & -5420 & 91.7 & 95.6 & 11.71 & .830 & 92.9 & & & & & 1.147 &. .952 \\
\hline 1035 & -99.0 & 95.1 & 3084 & 89.6 & -5650 & 95.2. & 99.1 & 12.12 & .822 & 95.8 & & & & & 1.159 & .952 \\
\hline 1036 & -95.9 & 56.6 & 1837 & 81.2 & -3341 & 71.3 & 77.8 & 7.43 & .882 & 68.2 & 264 & .991 & 480.9 & 441,6 & 1.070 & 926 \\
\hline 1037 & -95.9 & 64.4 & 2090 & 84.1 & -4520 & 79.8 & 83.5 & 9.05 & .847 & & & & & & 1.094 & .969 \\
\hline 1038 & -95.8 & 81.9 & 2657 & 91.0 & -5897 & 99.0 & 103.1 & 12.56 & .790 & 98.5 & & & & & 1.168 & .949 \\
\hline 1039 & -95.8 & 88.2 & 2861 & 94.2 & -6000 & 104.5 & 109.3 & 13.22 & .783 & 99.2 & & & & & 1.187 & .949 \\
\hline 1040 & -94.7 & 81.7. & 2651 & 92.2 & -6075 & 100.5 & 104.3 & 12.72 & .784 & 98.8 & & & & & 1,169 & .947 \\
\hline 1041 & -93.6 & 81.7 & 2628 & 93.6 & -5973 & 103,5 & 107.1 & 13.08 & .774 & 98.9 & & & & & 1.171 & 948 \\
\hline 1042 & -98.5 & 81.7 & 2652 & 87.8 & -5573 & 88.0 & 93.1 & & 817 & 92.2 & & & & & 1.141 & .952 \\
\hline 1043 & -96.4 & 81.8 & 2654 & 89.8 & -5999 & 94.4 & 98.4 & 12.17 & .797 & 96.2 & & & & & 1.164 & \begin{tabular}{|l}
.952 \\
\end{tabular} \\
\hline 1044 & -91.3 & 57.2 & 1851 & 83.1 & -3548 & 74.6 & 80.4 & 8.47 & .857 & 77.1 & .282 & 989 & 512.6 & 467.3 & 1.071 & .976 \\
\hline 1045 & -91.2 & 64.5 & 2090 & 85.8 & -4472 & 81.6 & 85.9 & & .827 & & & & & & 1.092 & \begin{tabular}{|l}
.973 \\
\end{tabular} \\
\hline 1046 & -93.6 & 57.4 & 1858 & 82.8 & -3788 & 74.0 & 79.1 & & .862 & & & & & & 1.076 & \begin{tabular}{|l}
974 \\
\end{tabular} \\
\hline 1047 & -93.6 & 64.3 & 2084 & 85.5 & -4497. & 81.3 & 85.3 & & .830 & & & & & & 1.100 & .970 \\
\hline 1048 & -93.6 & 79.1 & 2566 & 94.1 & -6194 & 103.4 & 107.4 & 3.11 & .772 & 99.1 & & & & & 1.165 & \begin{tabular}{|l}
.956 \\
\end{tabular} \\
\hline 1049 & -106.4 & 57.3 & 1860 & 75.1 & -2031 & 64.5 & 74.6 & & .943 & & & & & & 1.240 & $\begin{array}{r}285 \\
\end{array}$ \\
\hline 1050 & -106.4 & 64.4 & 2087 & 27.6 & -2635 & 66.6 & 75.2 & & .929 & & & & & & 1.047 & .979 \\
\hline 1051 & -106.4 & 81.8 & 2658 & 82,1 & -3703 & 74.5 & 80,5 & & .895 & & & & & & 1.075 & .967 \\
\hline 1052 & -106.4 & 87,9 & 2848 & 83.5 & -3930 & 78.3 & 83.2 & & .889 & & & & & & 1.081 & .953 \\
\hline 1053 & -106.4 & 95.4 & 3095 & 85,1 & -3932 & 81,6 & 86,2 & & .877 & & & & & & 1.086 & .958 \\
\hline 1054 & $-106,5$ & 88,0 & 2854 & 83.0 & -3720 & 77.0 & 82.7 & 7.59 & .894 & & & & & & 1.076 & .965 \\
\hline 1055 & -106.5 & 79,2 & 2569 & 80,9 & -3444 & 72.7 & 80,1 & 6,67 & .908 & & & & & & 1.063 & .970 \\
\hline 1056 & -93.6 & 56.4 & 1829 & 82.3 & -3696 & 73.4 & 79.5 & 7.94 & .870 & 72.5 & 273 & .989 & 494.6 & 453.4 & 1.071 & .974 \\
\hline 1057 & -94.2 & 56.4 & 1828 & 82.0 & -3420 & 72.8 & 79.2 & 6.74 & .874 & & & & & & 1.072 & 976 \\
\hline 1058 & $-94,2$ & 64,4 & 2038 & 84.9 & -4663 & 80.2 & 85.0 & 7.96 & .835 & & & & & & 1.096 & .967 \\
\hline 1059 & $-94,2$ & 82.8 & 2688 & 94.2 & -6160 & 104.1 & 107.6 & .13 .14 & .779 & 99.8 & & & & & 1.179 & .952 \\
\hline & & & & & & & & & & & & & & & & \\
\hline & & & & & & & & & & & & & & & & \\
\hline & & & & & & & & & & & & & & & & \\
\hline & & & & & & & & & & & & & & & & \\
\hline & & & & & & & & & & & & & & & & \\
\hline & & & & & & & & & & & & & & & & \\
\hline & & & & & & & & & & & & & & & & \\
\hline & & & & & & & & & & & & & & & & \\
\hline & & & & & & & & & & & & & & & & \\
\hline & & & & & & & & & & & & & & & & \\
\hline & & & & & & & & & & & & & & & & \\
\hline & & & & & & & & & & & & & & & & \\
\hline & & & & & & & & & & & & & & & & \\
\hline & & & & & & & & & & & & & & & & \\
\hline & & & & & & & & & & & & & & & & \\
\hline & & & & & & & & & & & & & & & & \\
\hline
\end{tabular}


APPENDIX D - STEADY-STATE REVERSE PERFORMANCE MOVABLE FLAPS

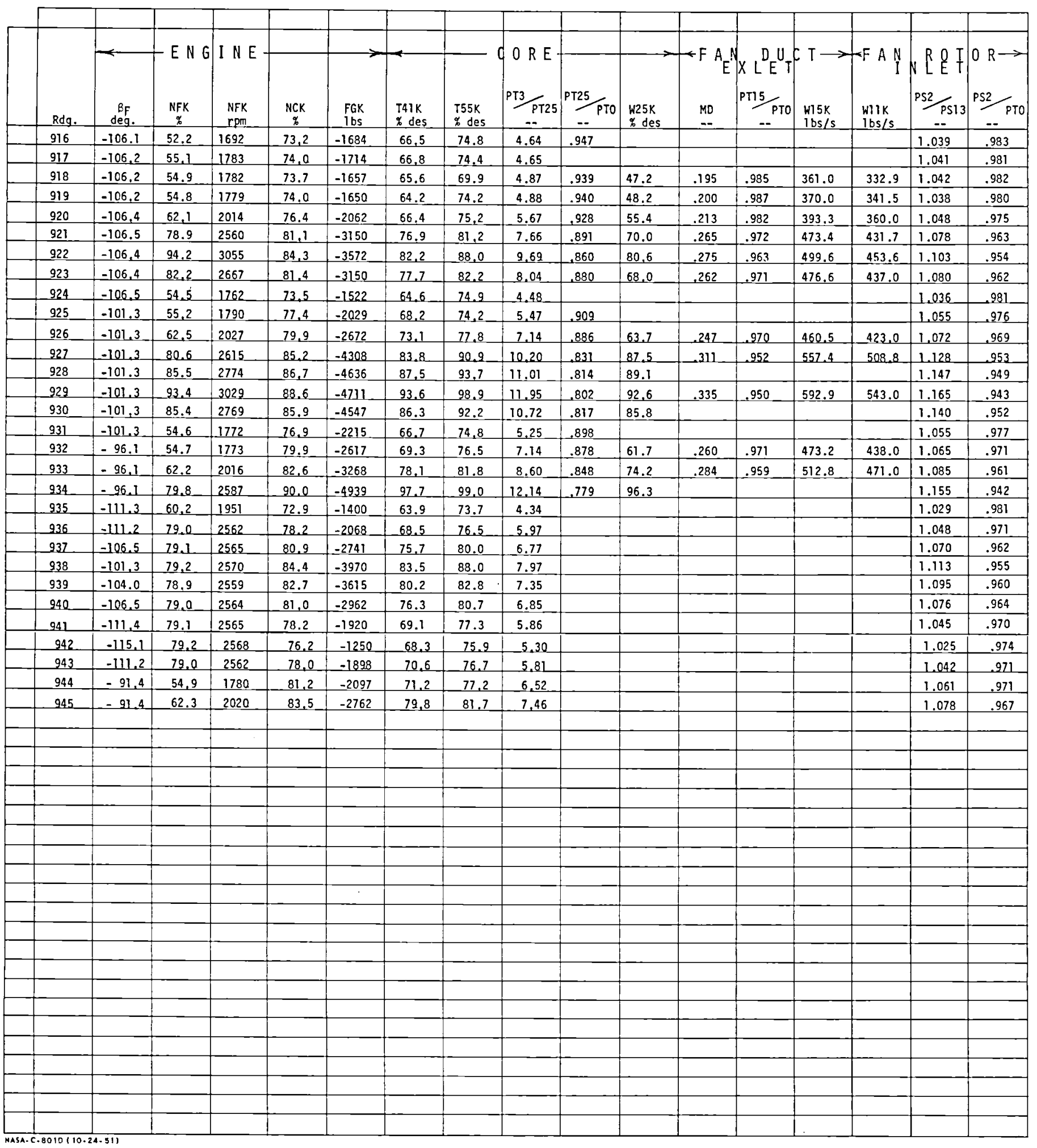


APPENDIXE - TRANSIENT PERFORMANCE

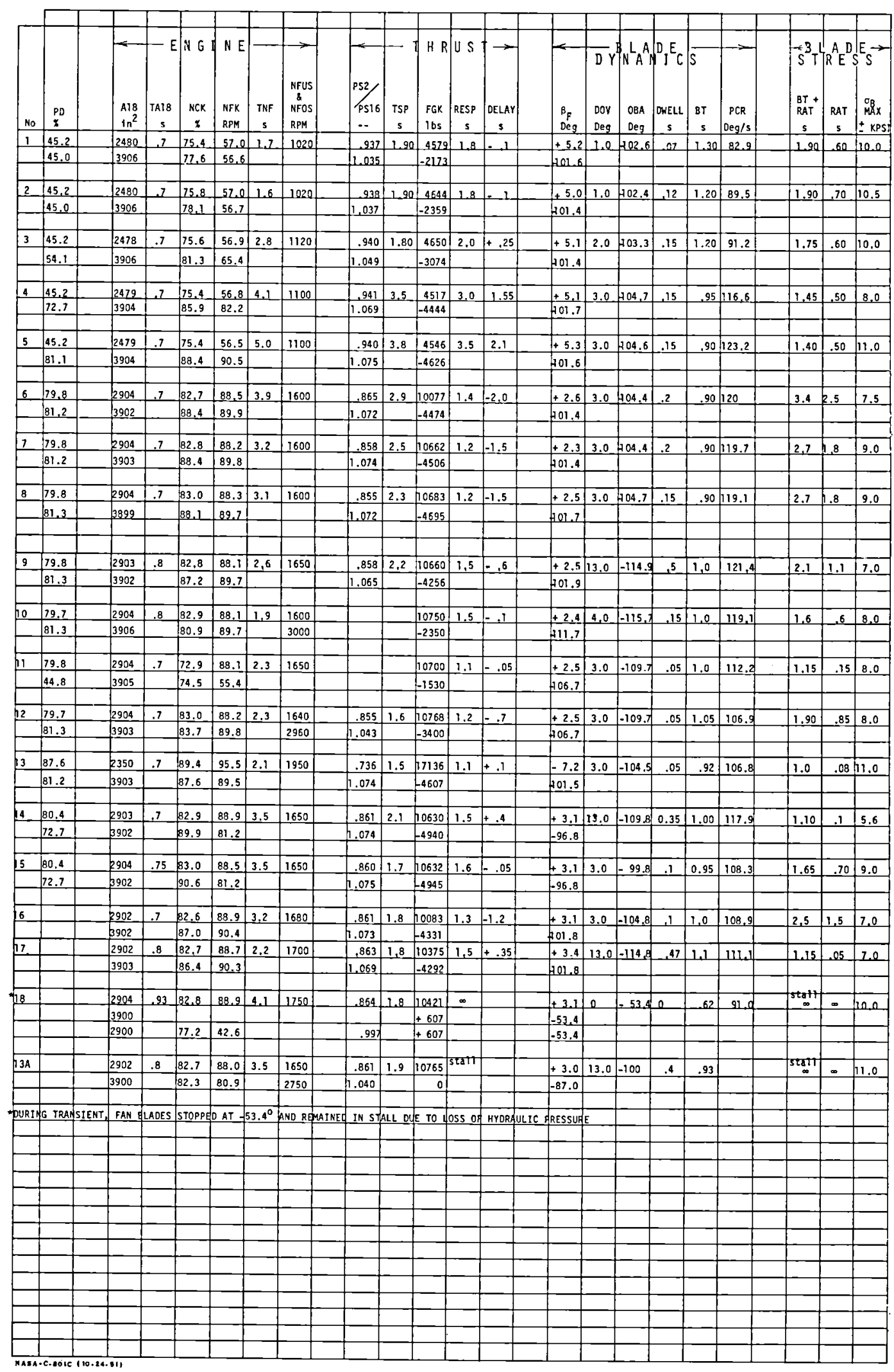




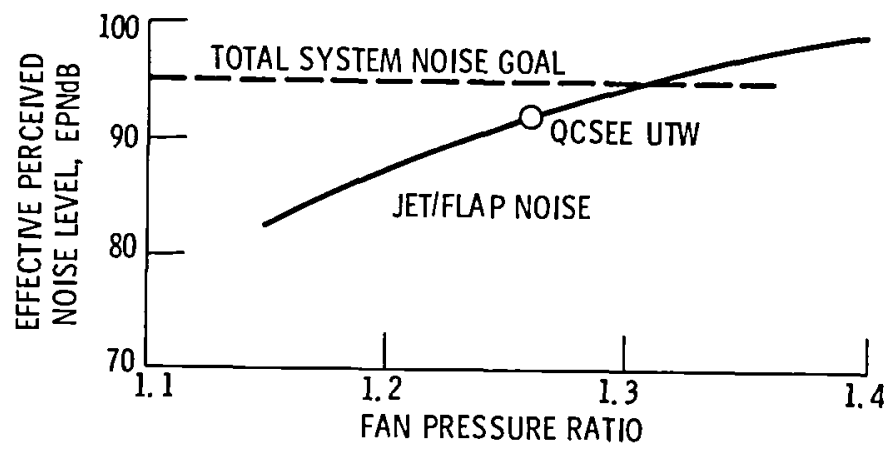

Figure 1. - Effect of jet flap noise on fan pressure ratio selection.

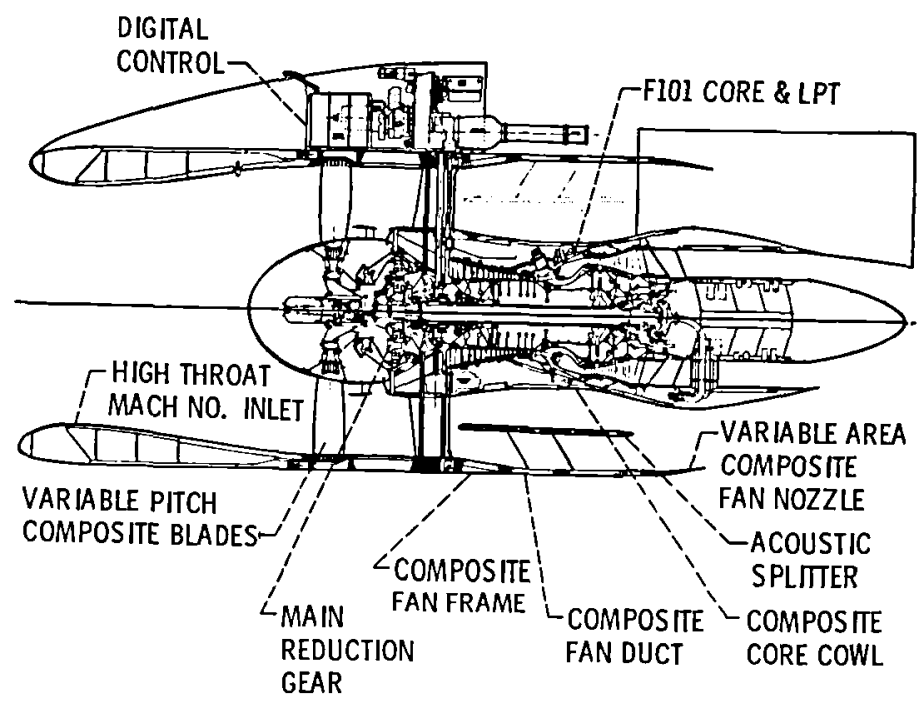

Figure 2. - UTW Engine cross section. 


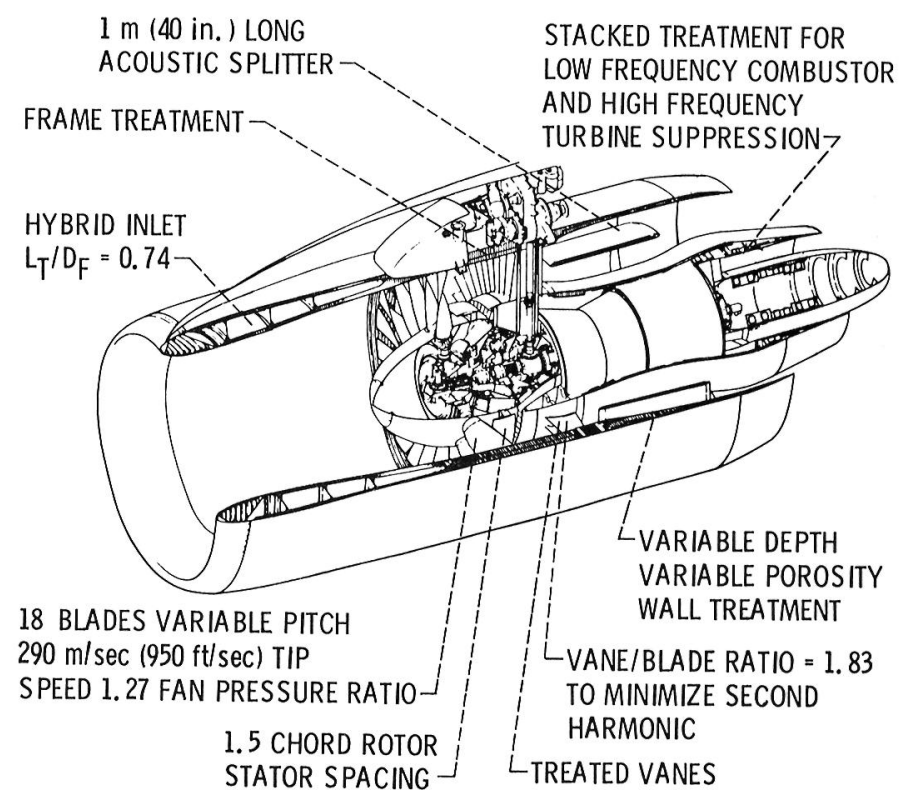

Figure 3. - Acoustic design features of QCSEE UTW engine.

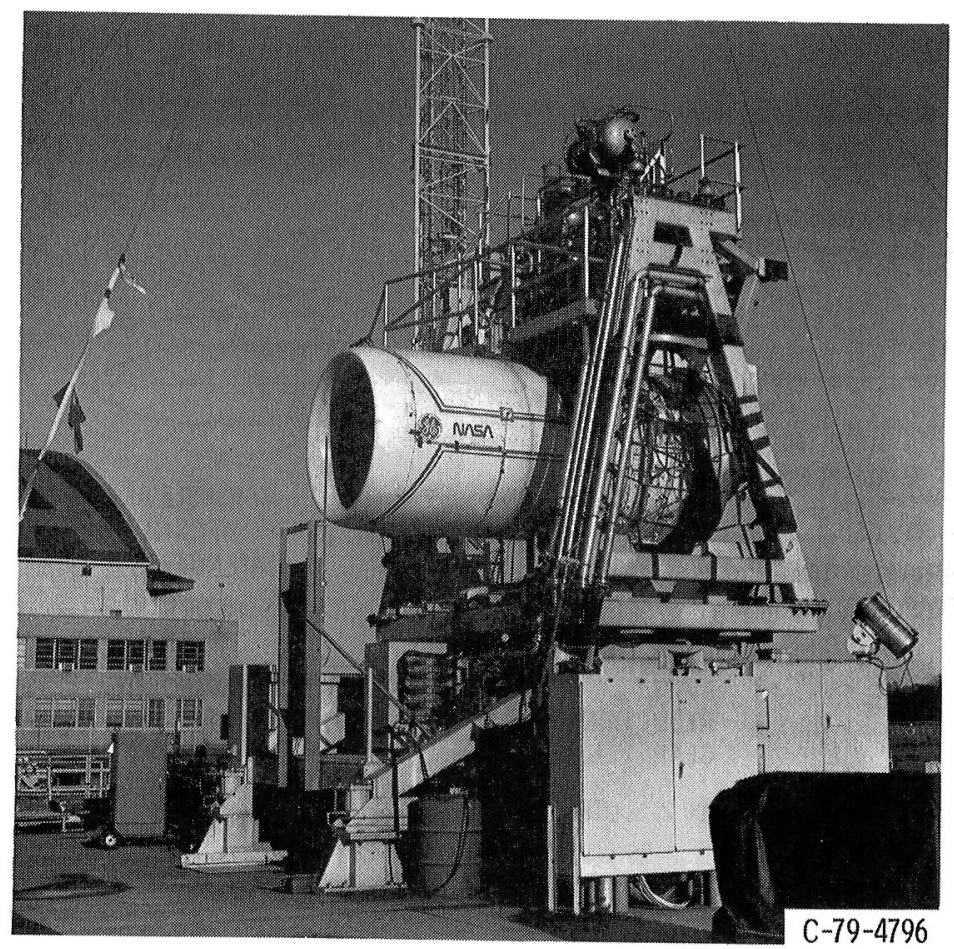

Figure 4. - Engine test stand - front view. 


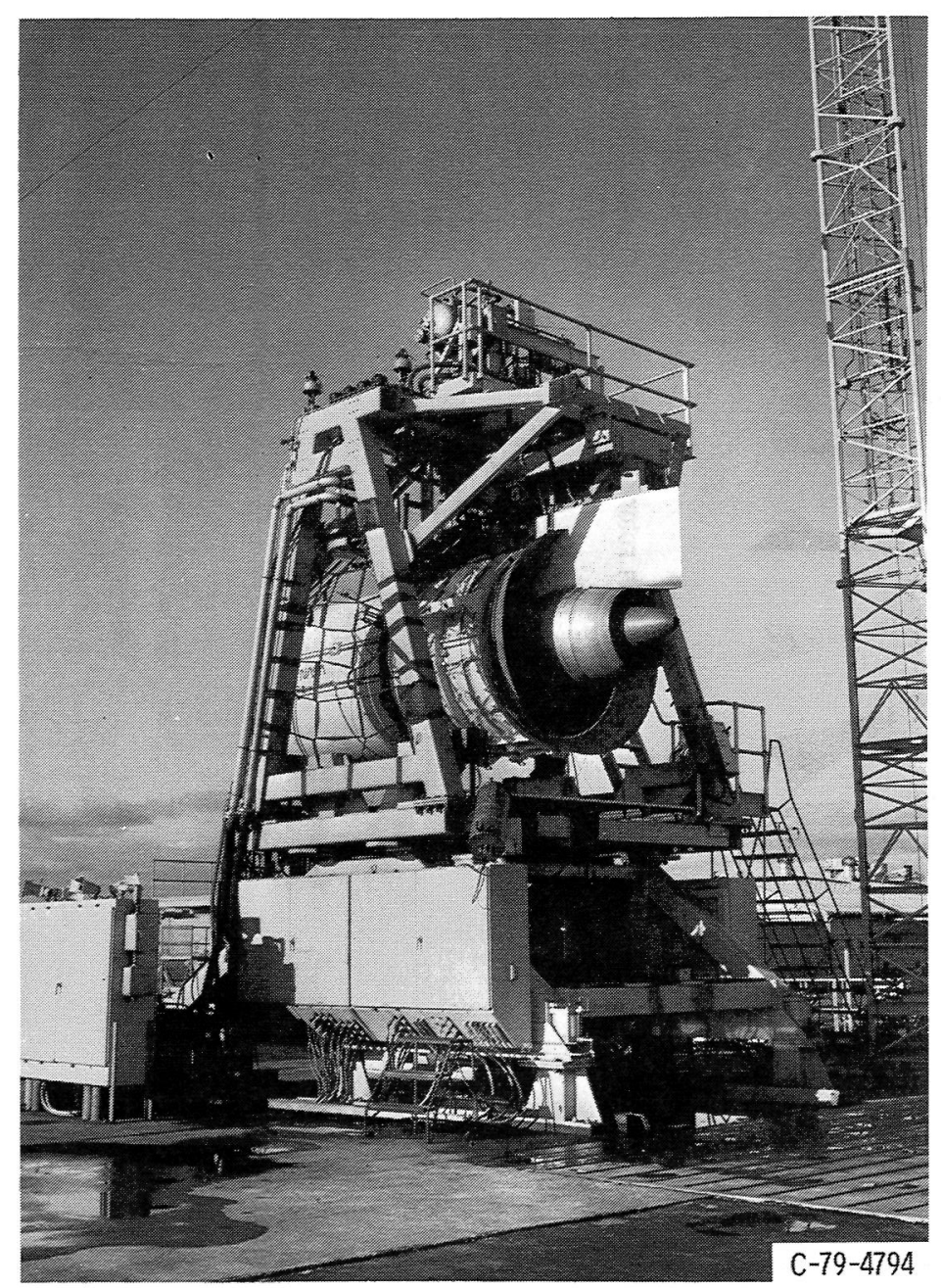

Figure 5. - Engine test stand-aft view.

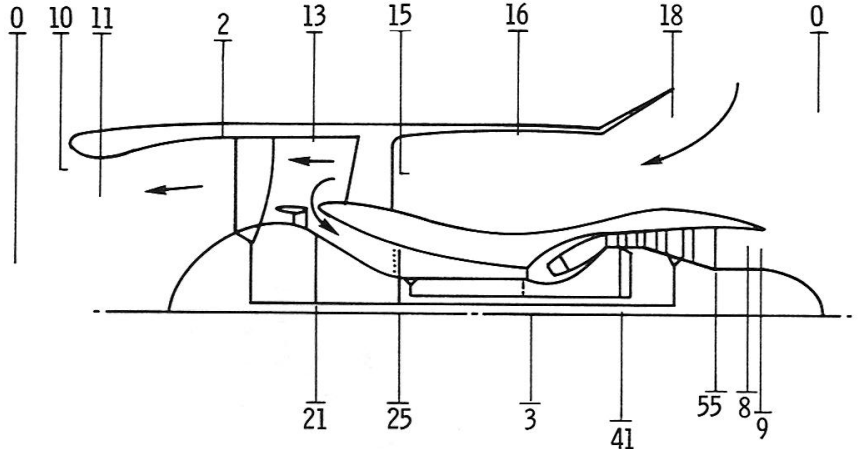

STATION

FREE STREAM AIR CONDITIONS

10 RADIAL TRAVERSE (FAN DISCHARGE P $\mathrm{P}_{\mathrm{T}}, 4$ " FORWARD OF INLET HIGHLIGHT)

11 INLET THROAT (FAN DISCHARGE, PS

FAN FRONT FACE (FAN DISCHARGE, PS)

FAN HUB DISCHARGE (INLET TO GOOSENECK)

HP COMPRESSOR INLET (RADIAL TOTAL PRESS \& TEMP RAKES) HP COMPRESSOR DISCHARGE (STATOR EXIT)

HP TURBINE ROTOR INLET

LP TURBINE FRAME DISCHARGE, EGT

PRIMARY EXHAUST NOZZLE THROAT

PRIMARY EXHAUST NOZZLE DISCHARGE

ROTOR INLET - FAN ROTOR TIP INLET PS

BYPASS DUCT (FAN INLET - RADIAL TRAVERSE AT BYPASS OGV TRAILING EDGE, $\mathrm{P}_{\mathrm{T}}, \mathrm{T}_{\mathrm{T}}$

BYPASS DUCT - (STATION 225 - FAN INLET FLOW MEASUREMENT PS'

8 BYPASS EXHAUST NOZZLE DISCHARGE (EXLET TRAILING EDGE)

Figure 6. - Station designations - reverse thrust configuration. 


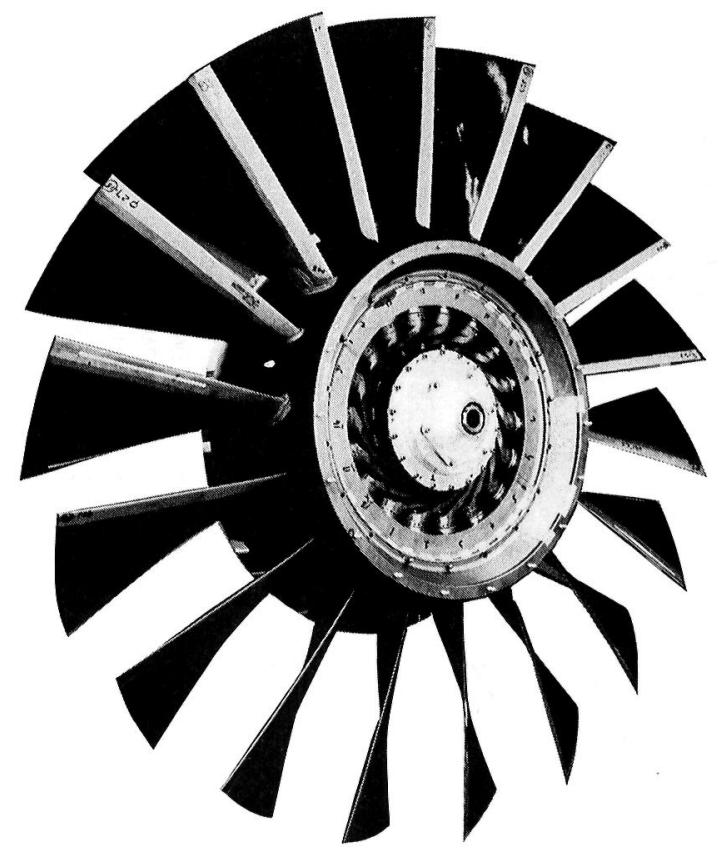

Figure 7. - UTW fan rotor. 


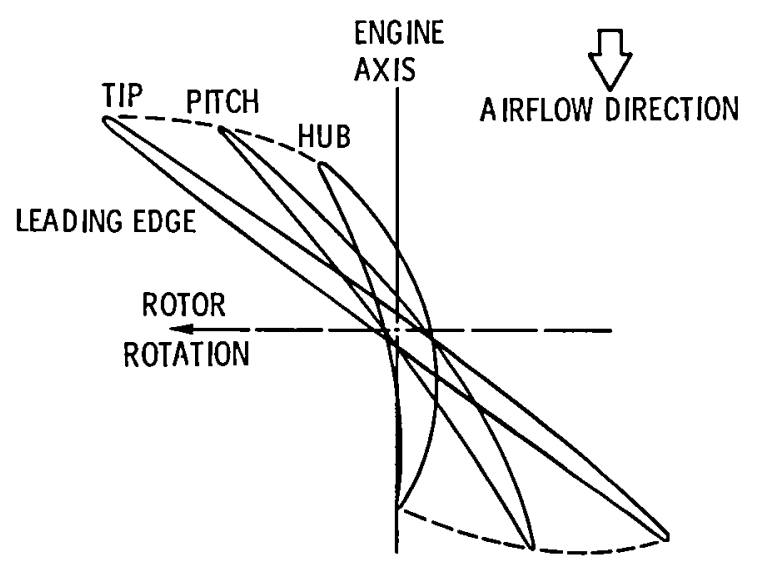

(a) Forward-mode operation.

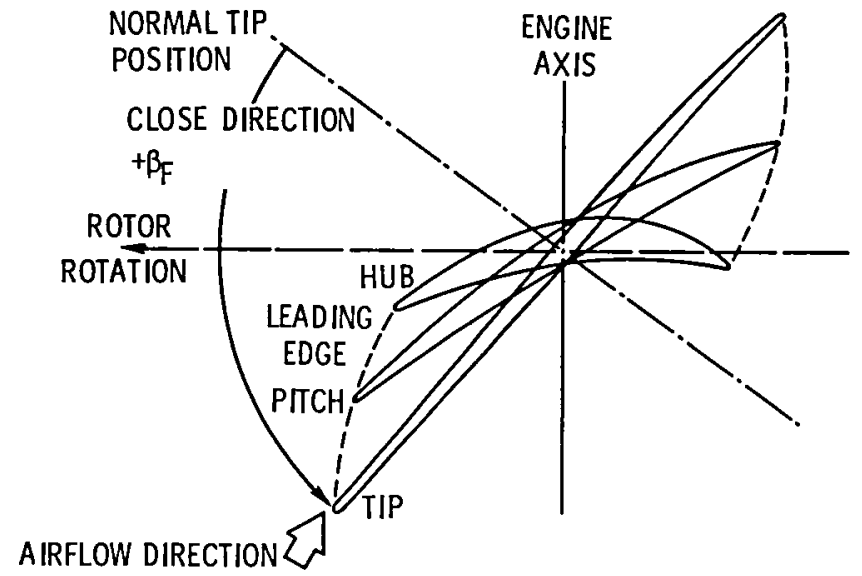

(b) Reverse through flat pitch speration.

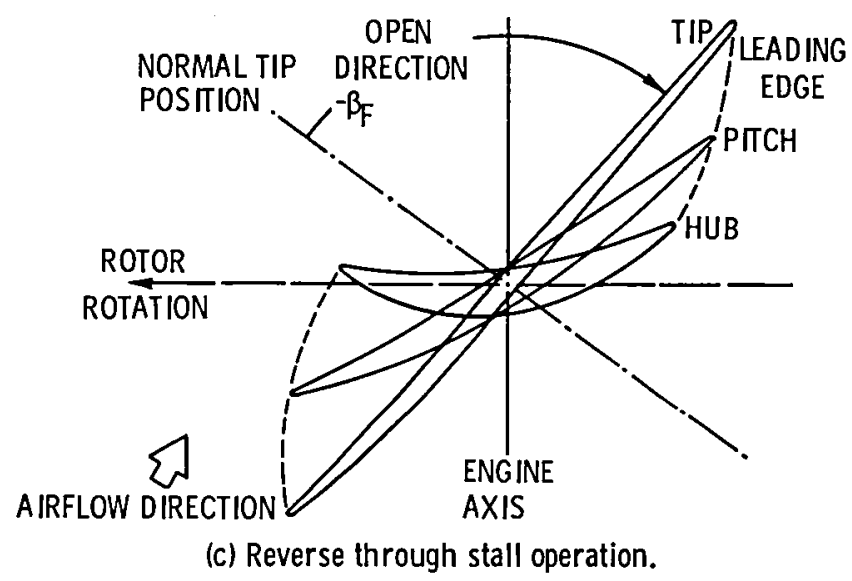

Figure 8. - UTW fan rotor blade. 


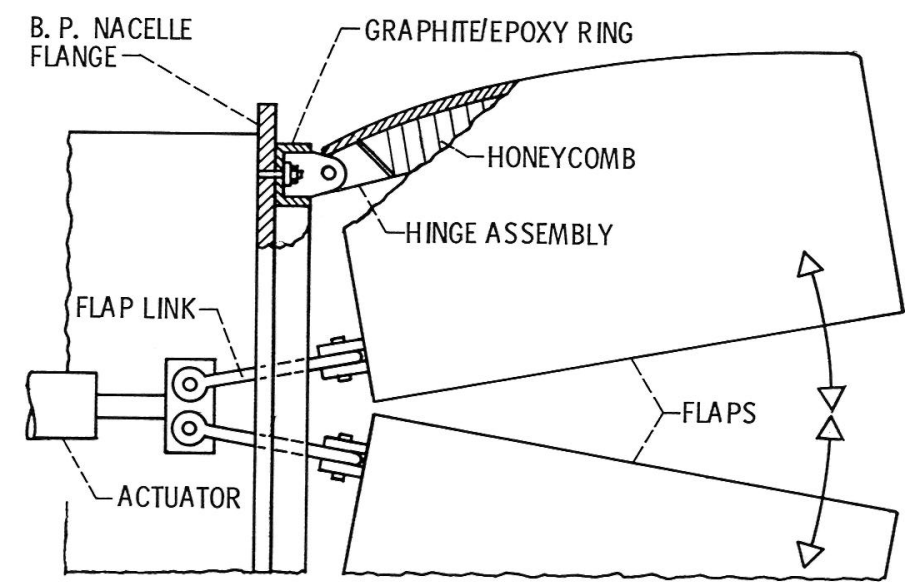

Figure 9. - Schematic-movable flaps.

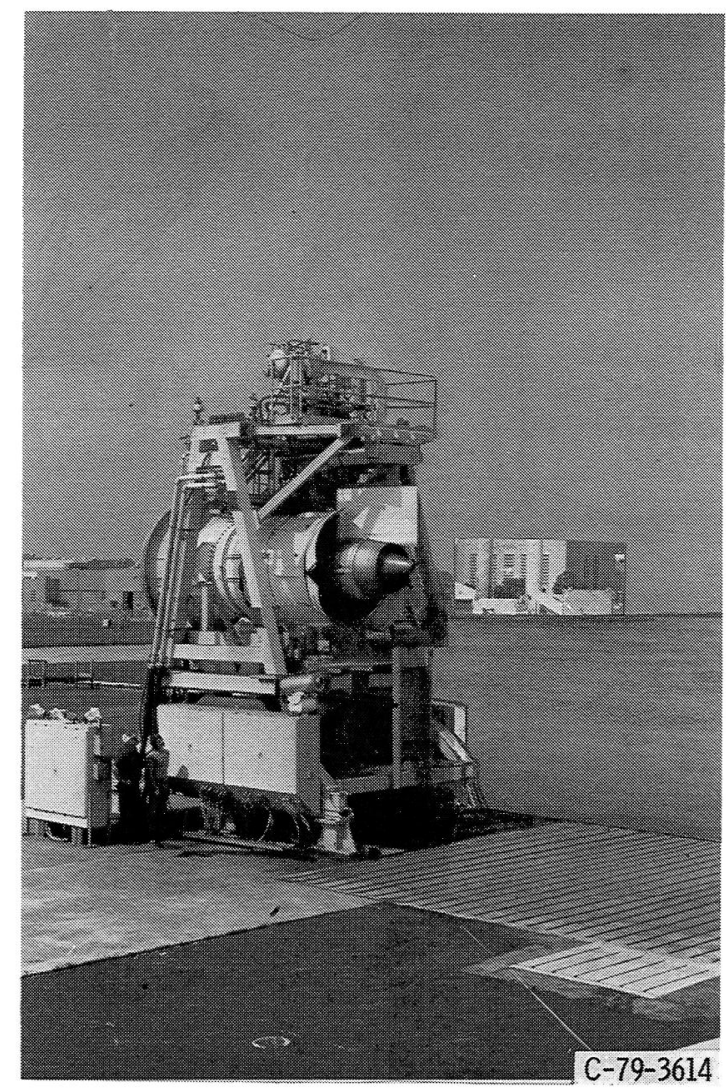

Figure 10. - 3/4 Aft view of movable flap configuration "on-test." 


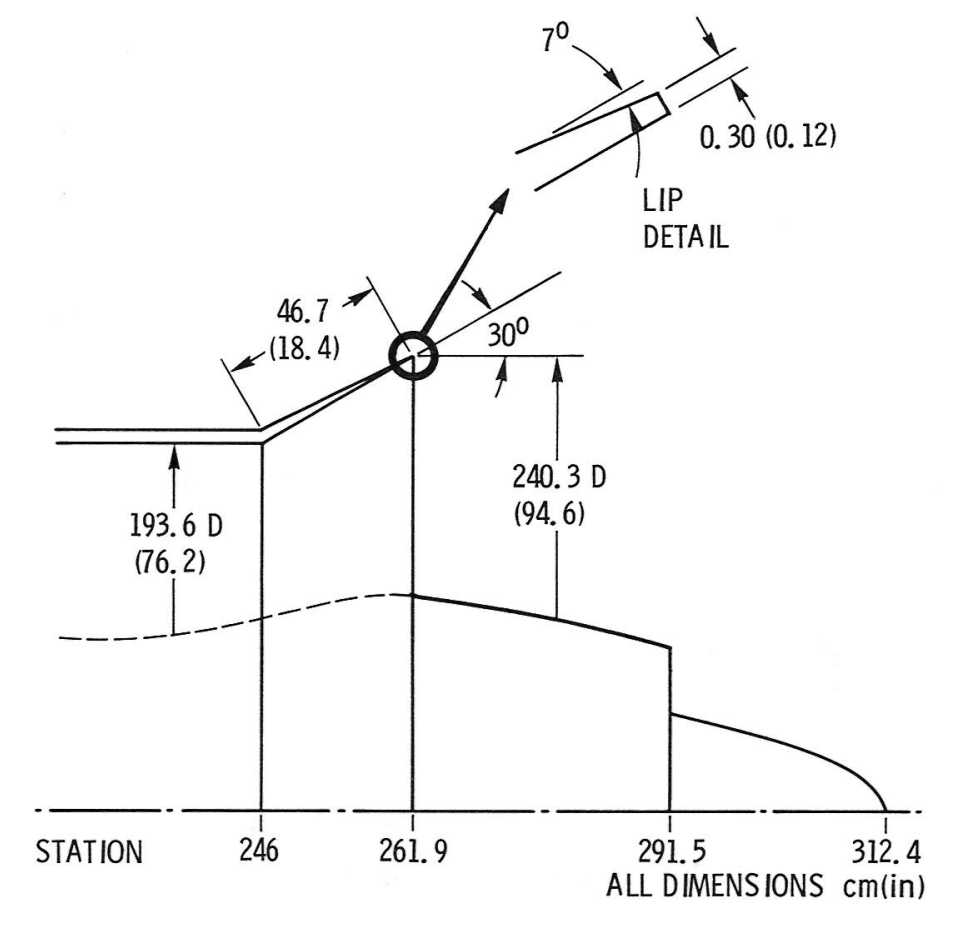

Figure 11. - Schematic-fixed $30^{\circ}$ exlet.

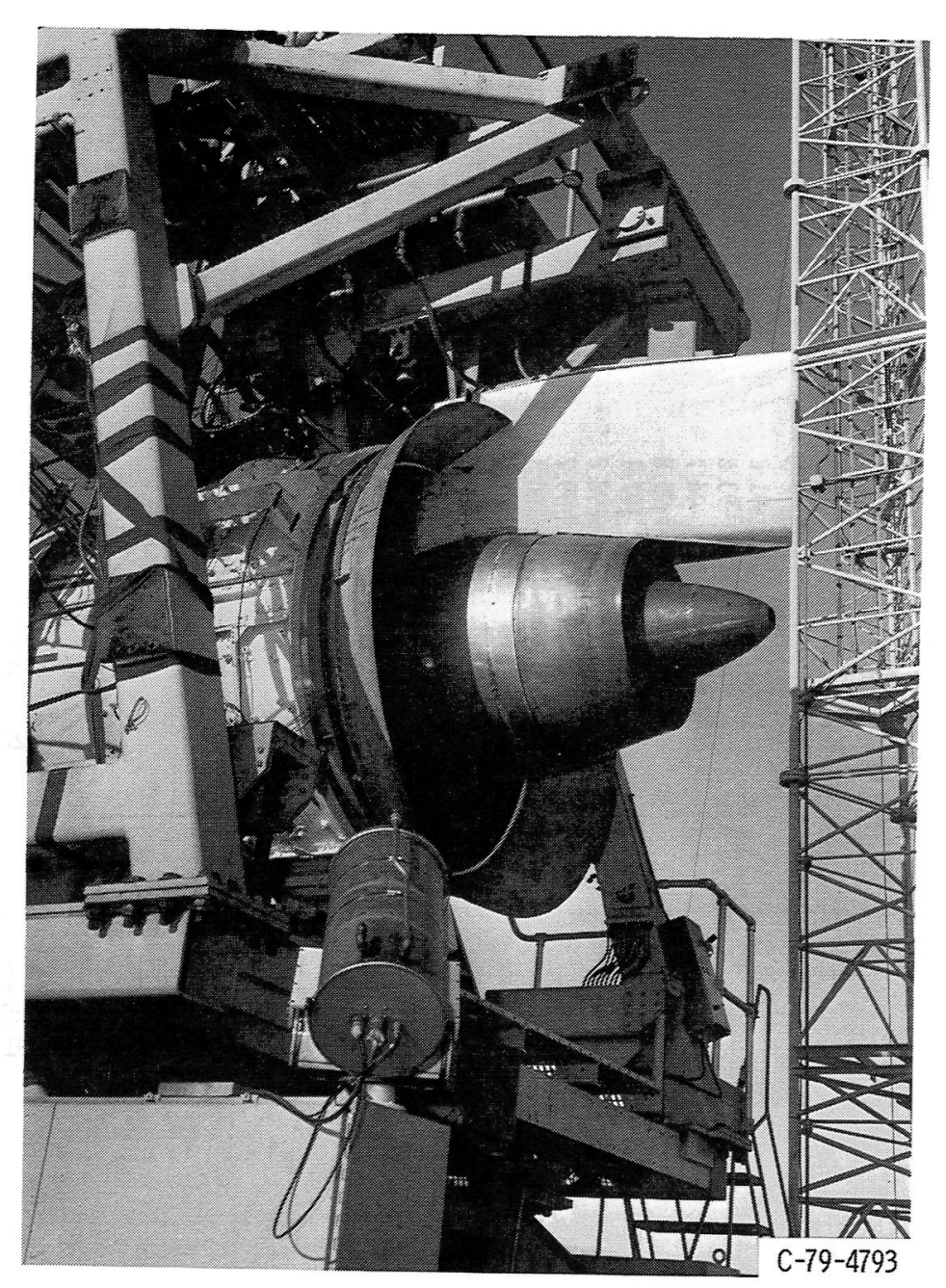

Figure 12. - Fixed $30^{\circ}$ exlet on-test. 


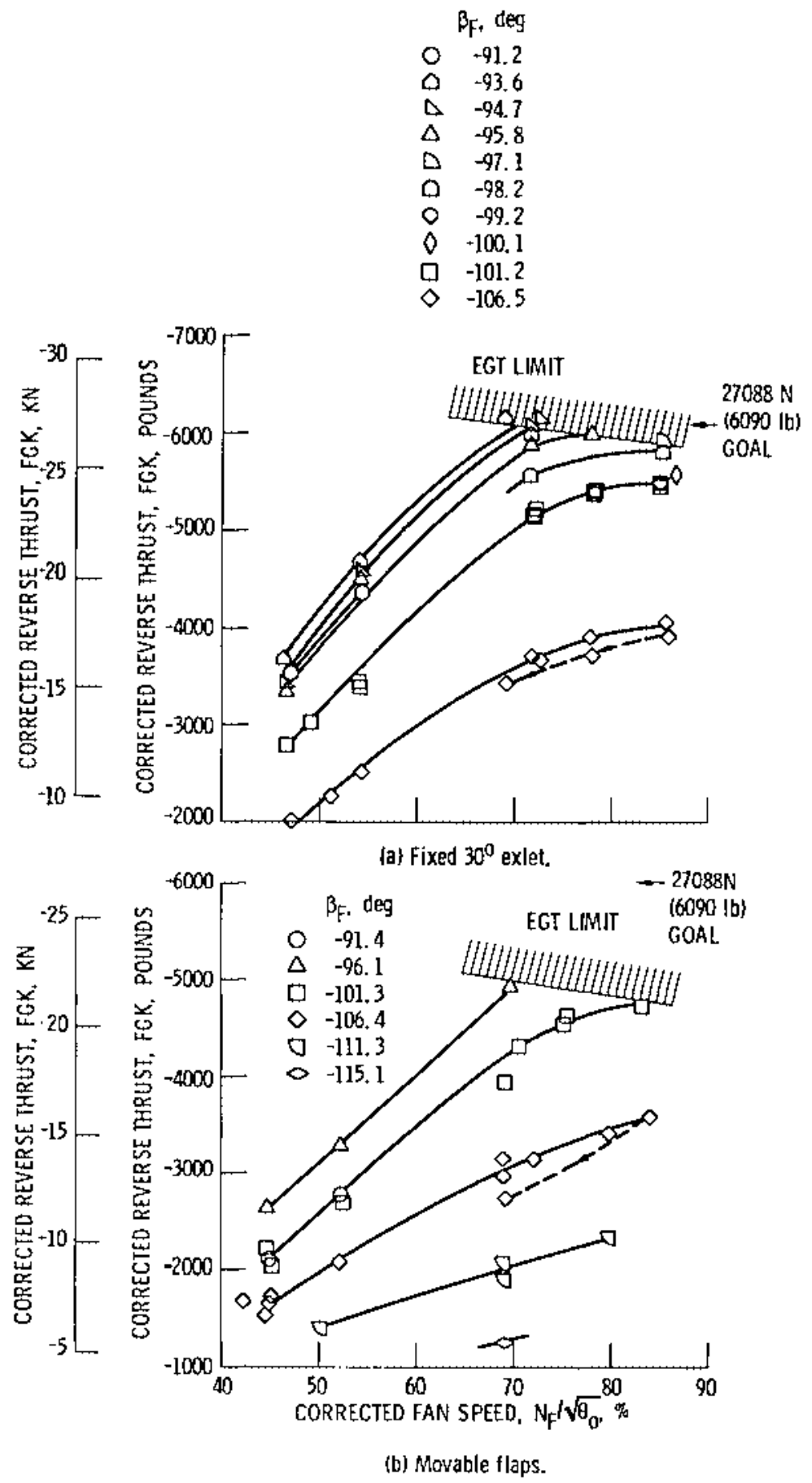

Figure 13. - Reverse thrust-fan speed characteristics. 


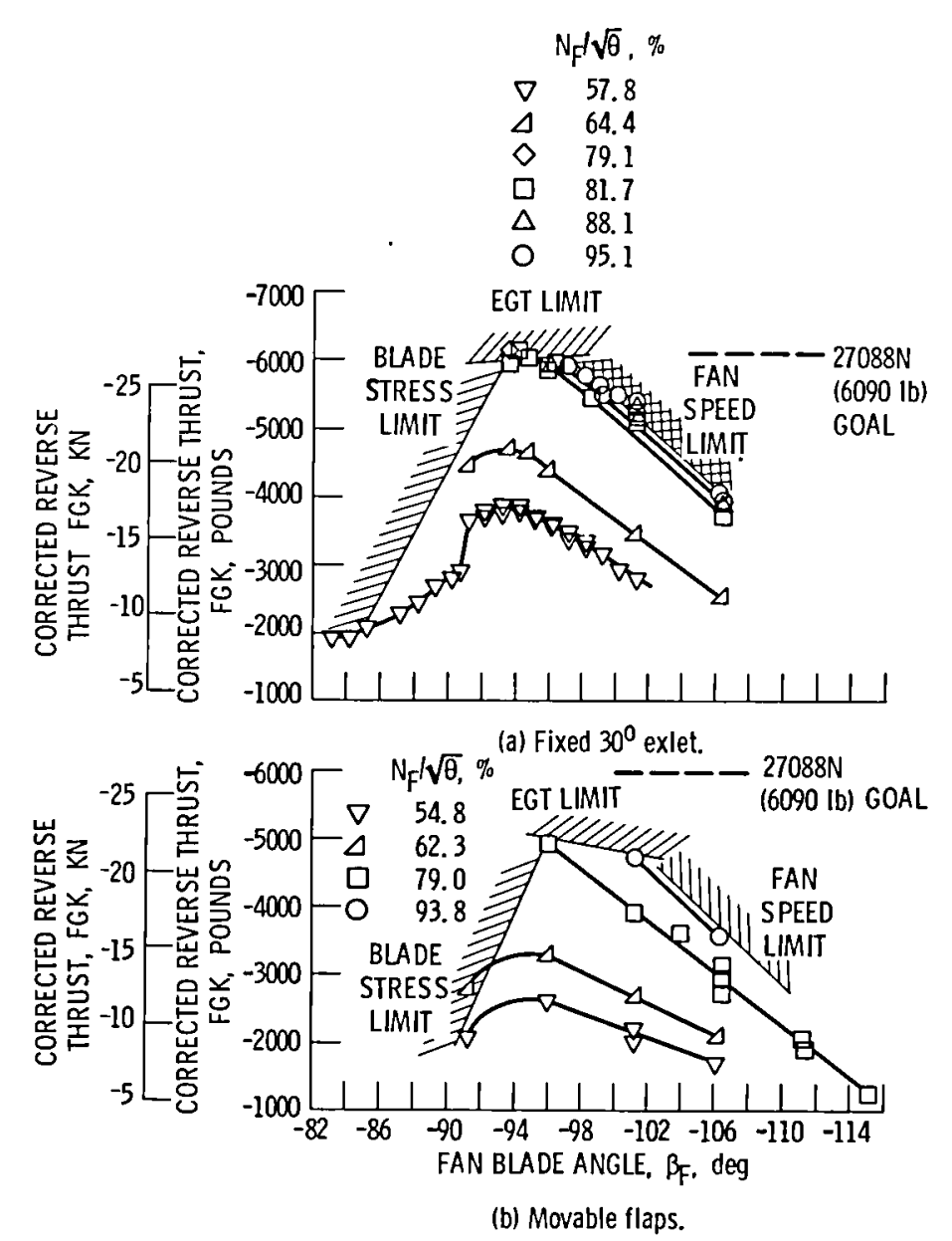

Figure 14. - Reverse thrust-fan blade angle characteristics.

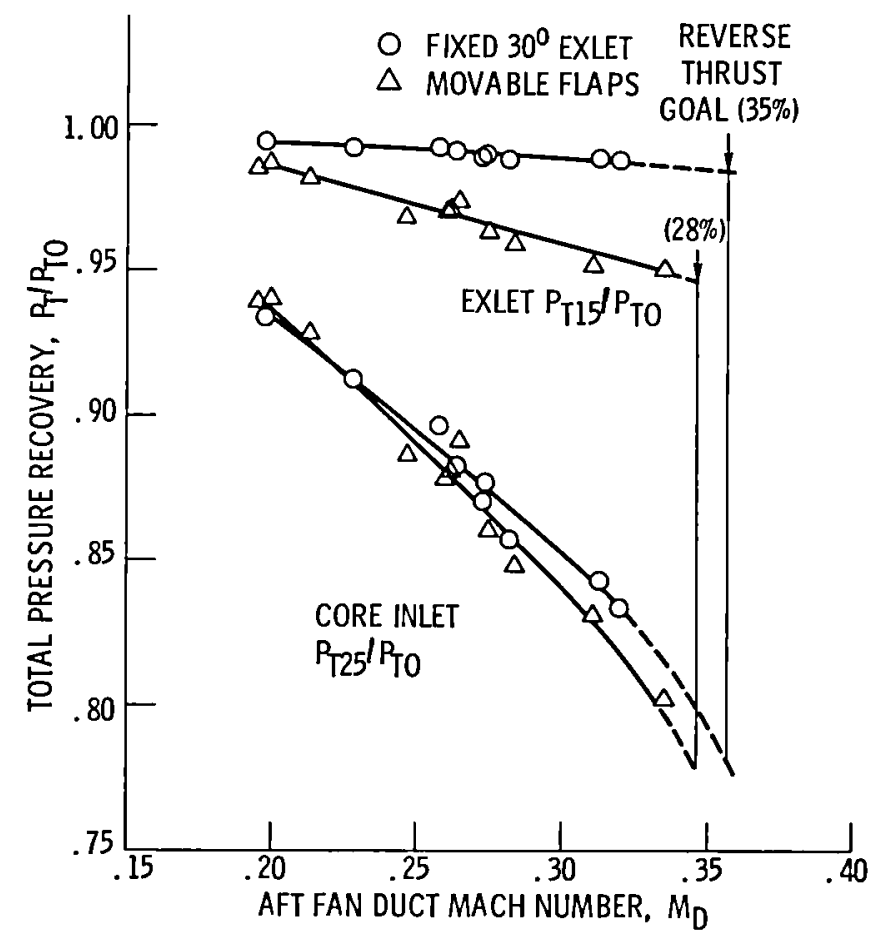

Figure 15. - Exlet and core inlet average total pressure recovery. 


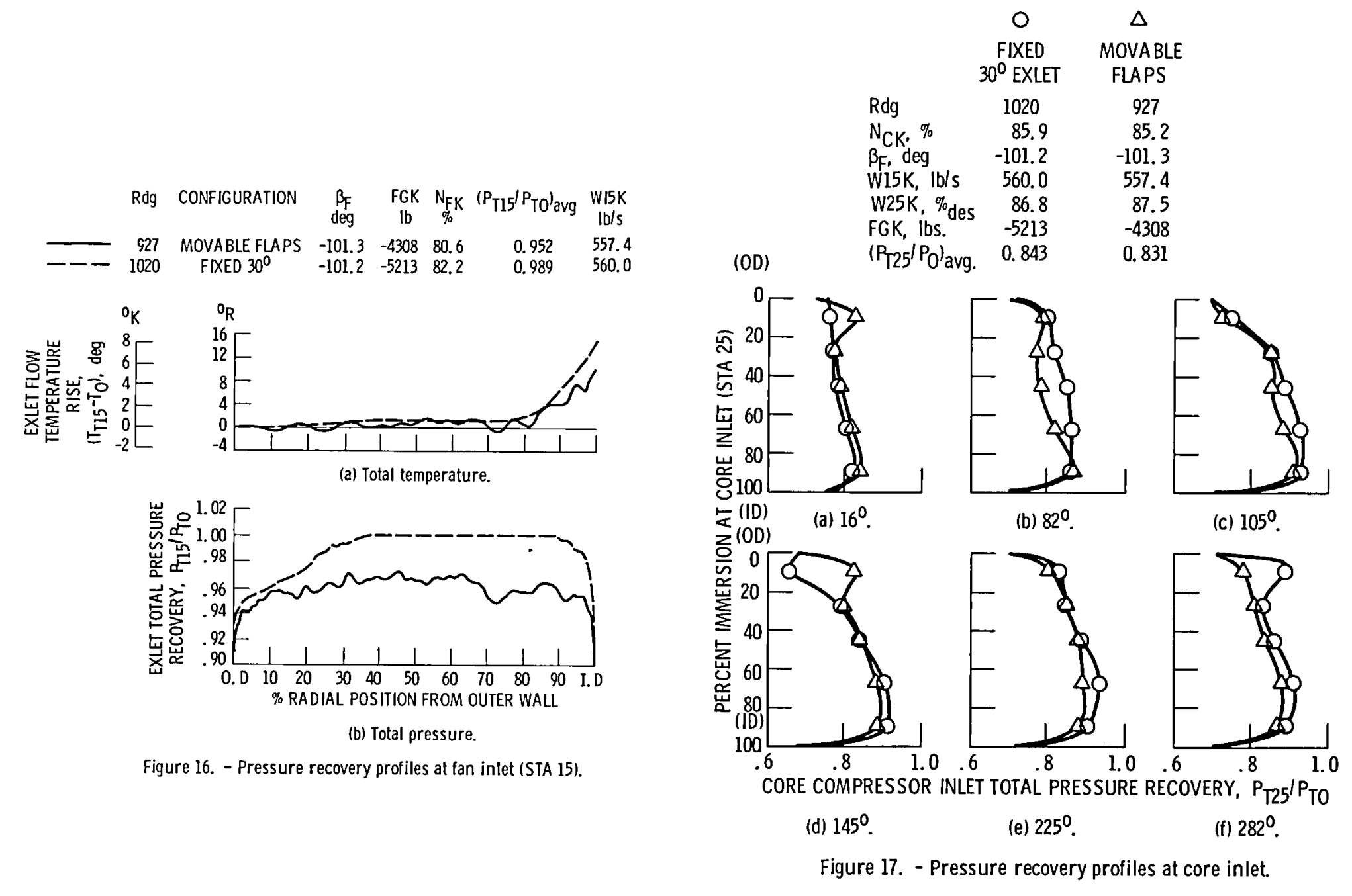



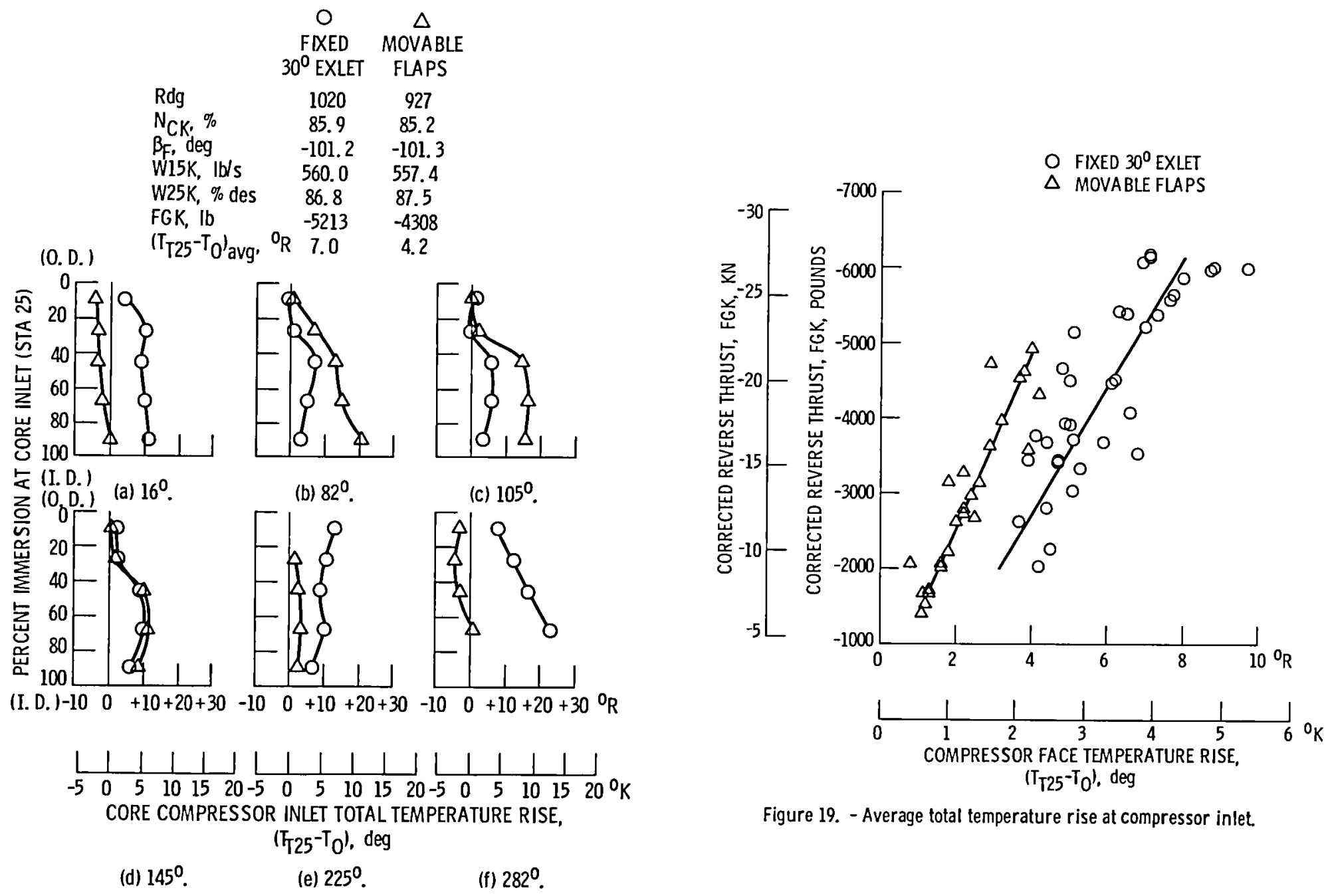

Figure 19. - Average total temperature rise at compressor inlet.

Figure 18. - Compressor inlet total temperature profiles. 


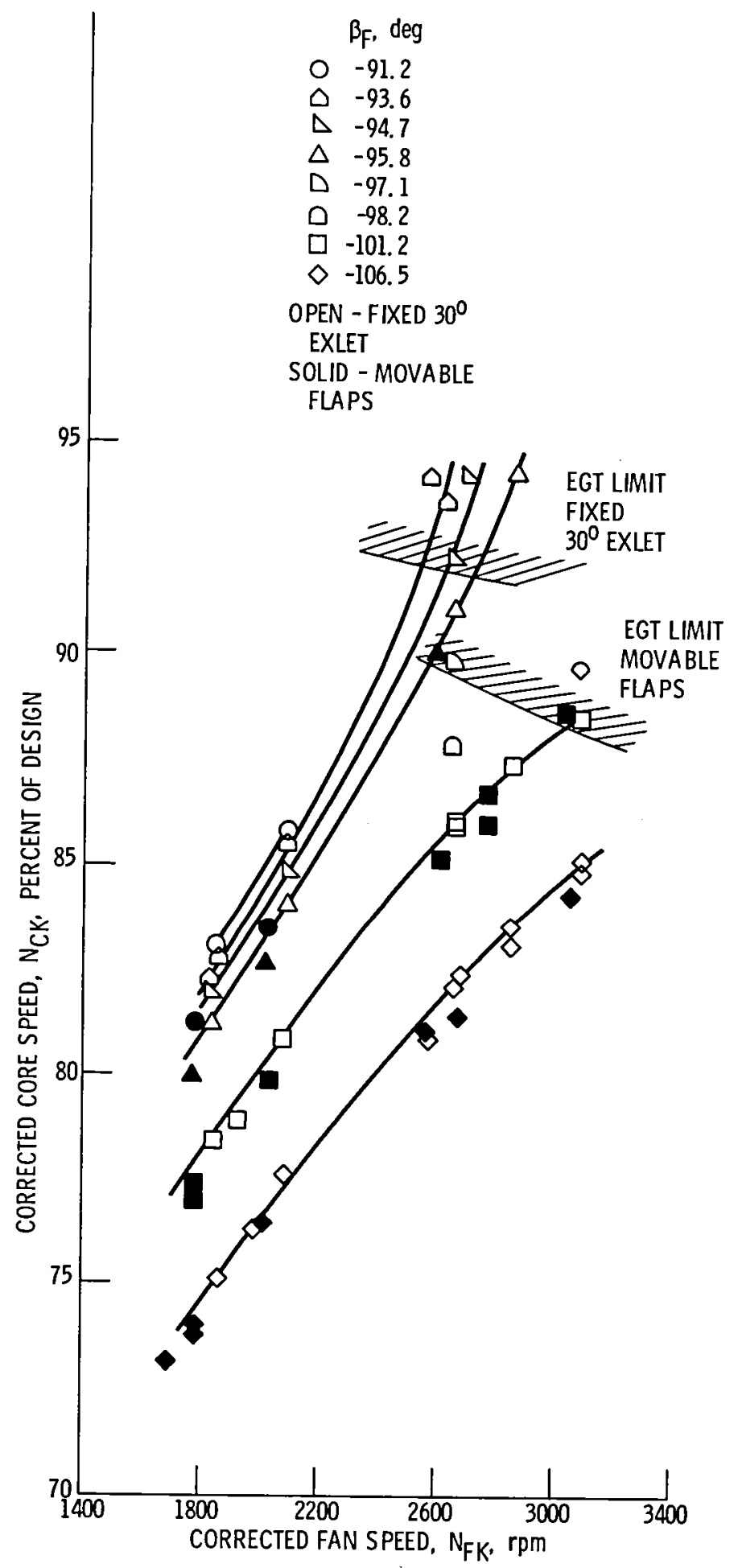

Figure 20. - Fan speed-core speed characteristics. 

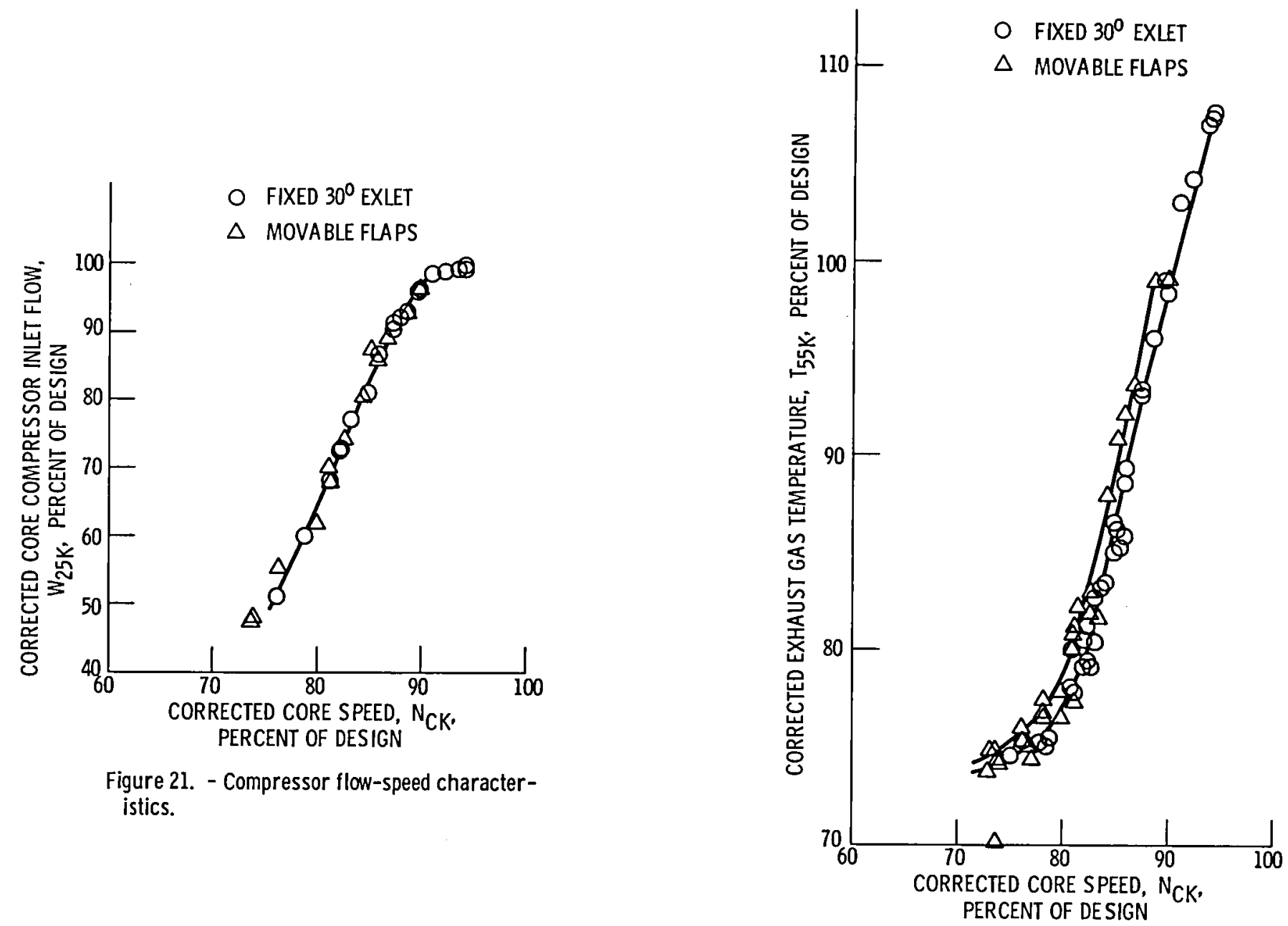

Figure 22. - Exhaust gas-core speed characteristics. 


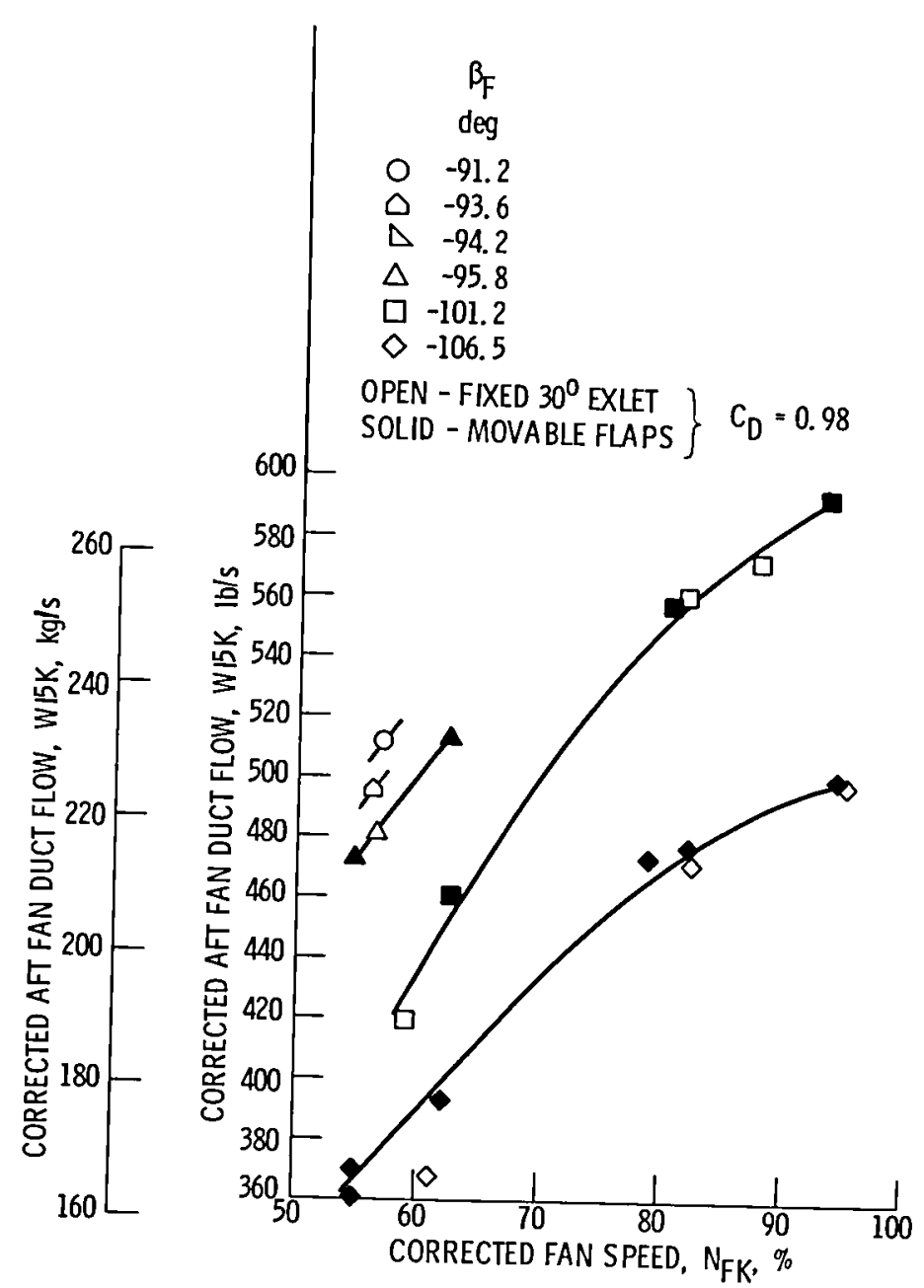

Figure 23. - Reverse air flow-fan speed characteristics.

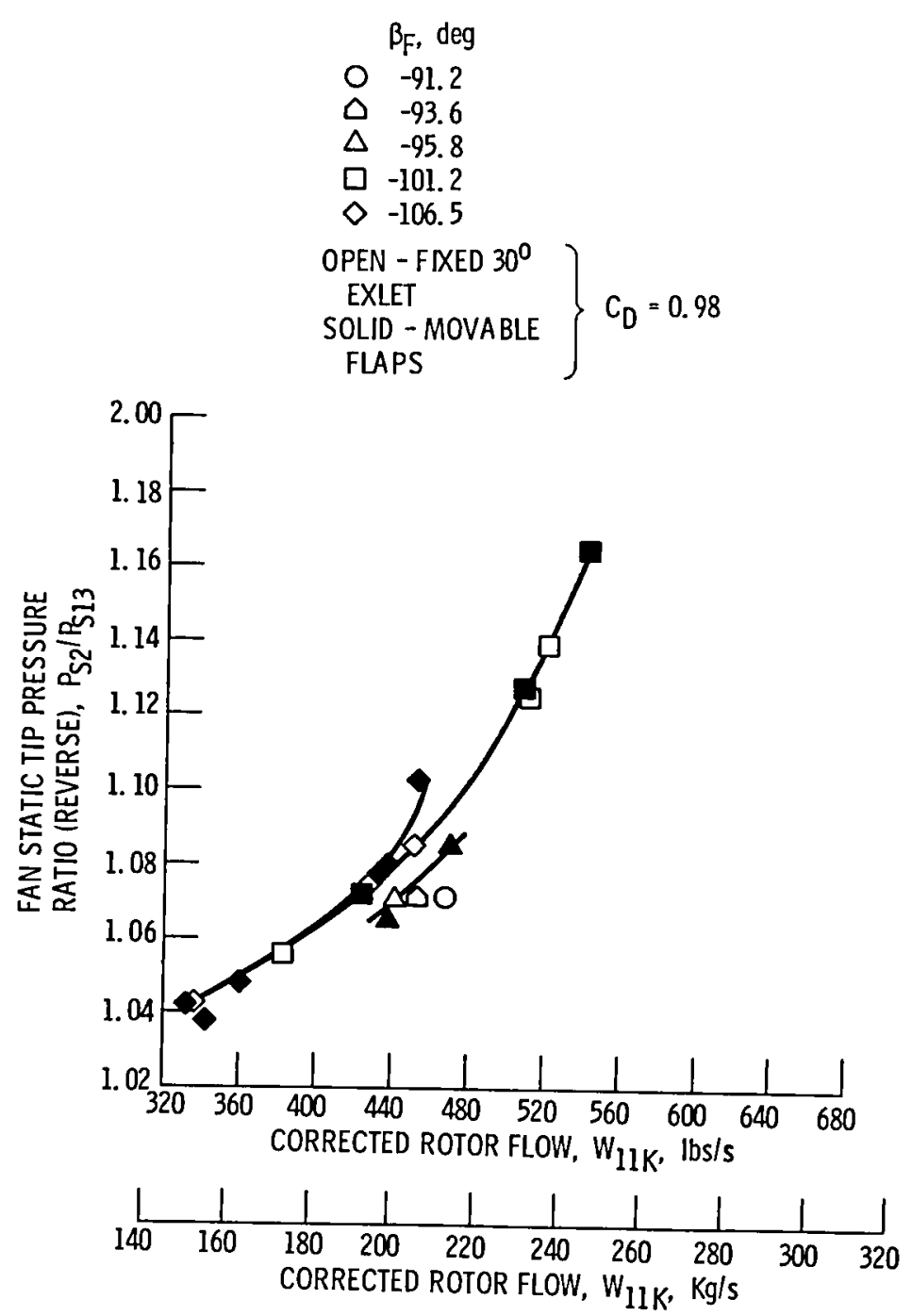

Figure 24. - Fan static pressure ratio-flow characteristics. 
Rdg CONFiguration $\beta_{F}$ FGK $\mathrm{N}_{\mathrm{FK}}\left(\mathrm{P}_{\mathrm{T} 15} / \mathrm{P}_{\mathrm{TO}}\right)_{\text {avg }}$ W15K Ib/s

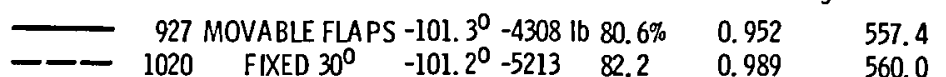

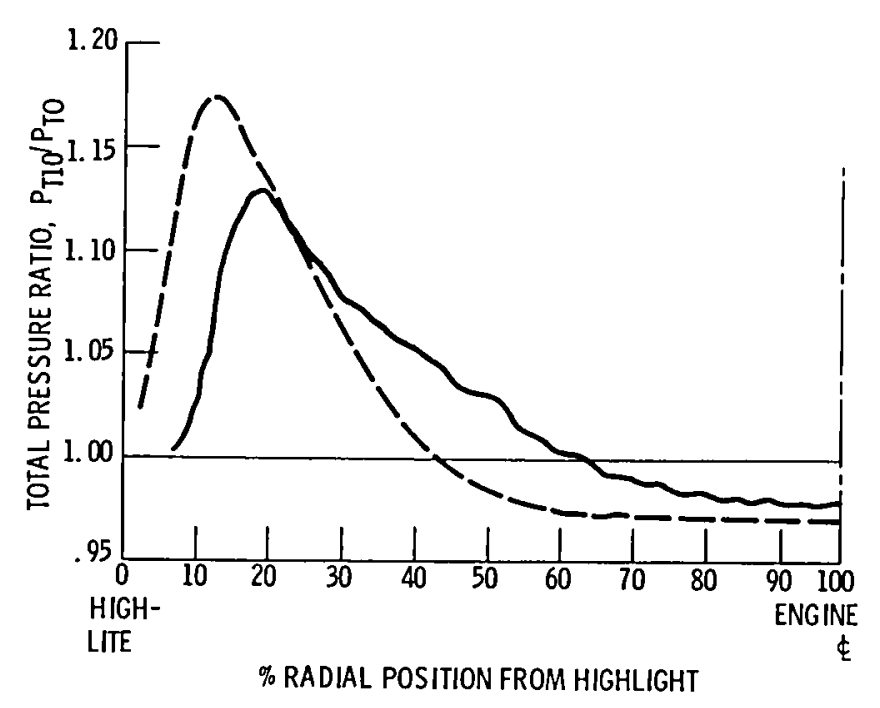

Figure 25. - Total pressure profiles at fan nozzle discharge (inlet highlight).

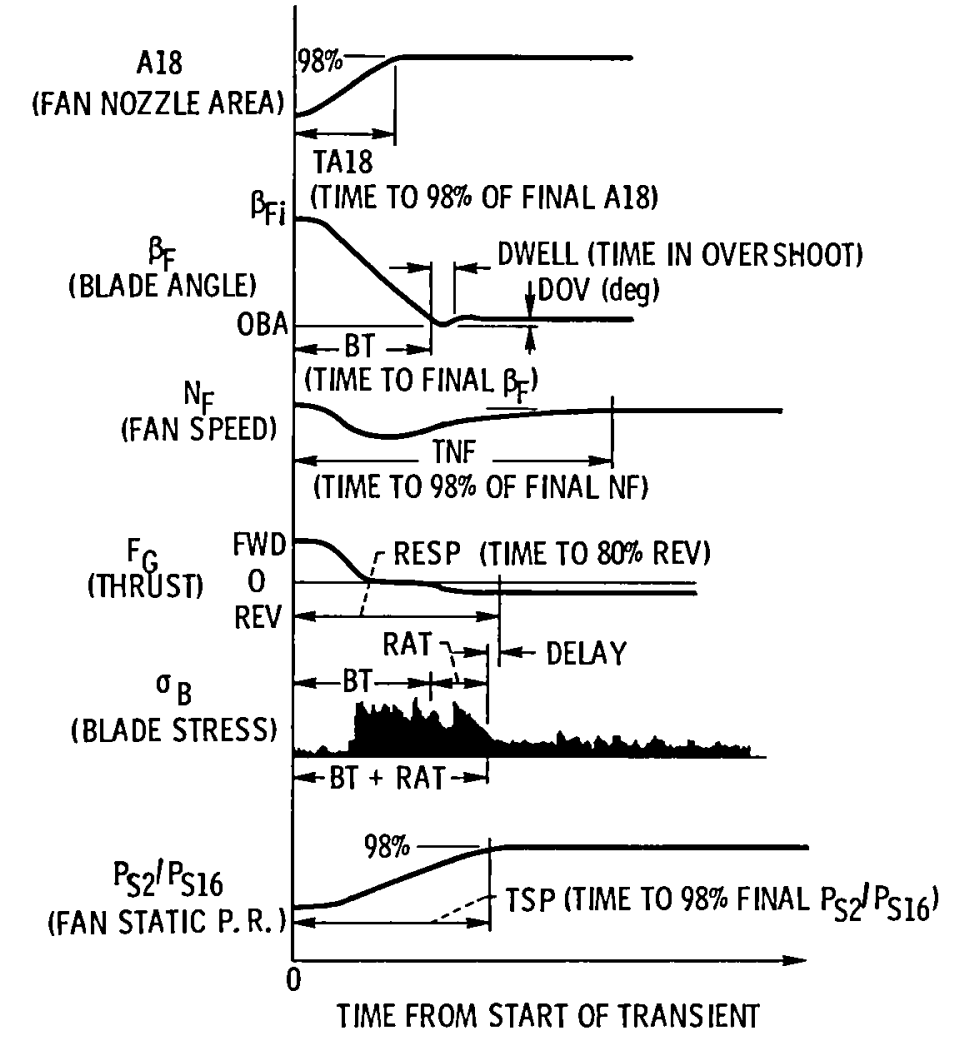

Figure 26. - Nomenclature for forwardto-reverse thrust transients. 

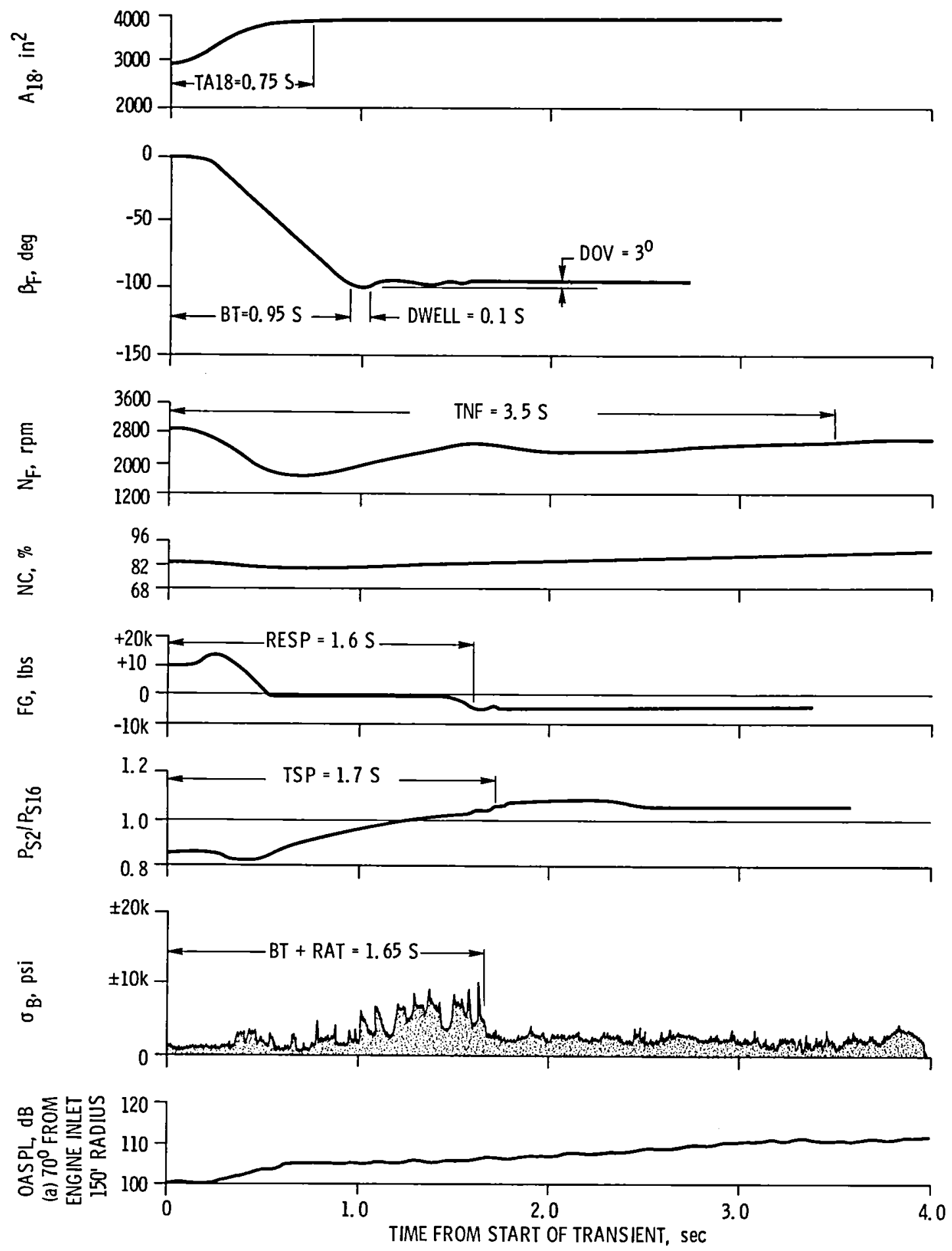

Figure 27. - Approach-to-reverse transient (\#15) with no blade overshoot. 

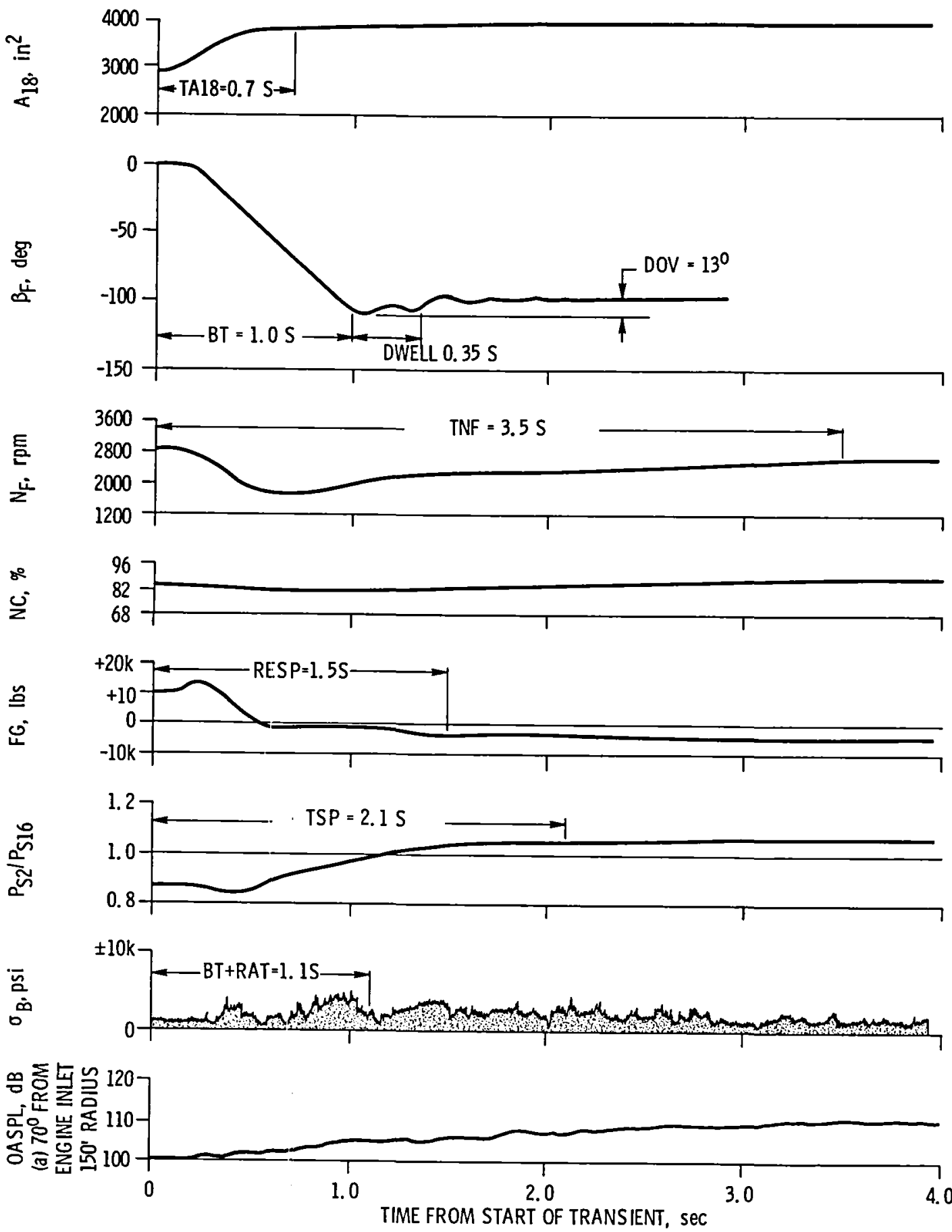

Figure 2.8. - Approach-to- reverse transient (\#14) with $10^{\circ}$ blade overshoot. 

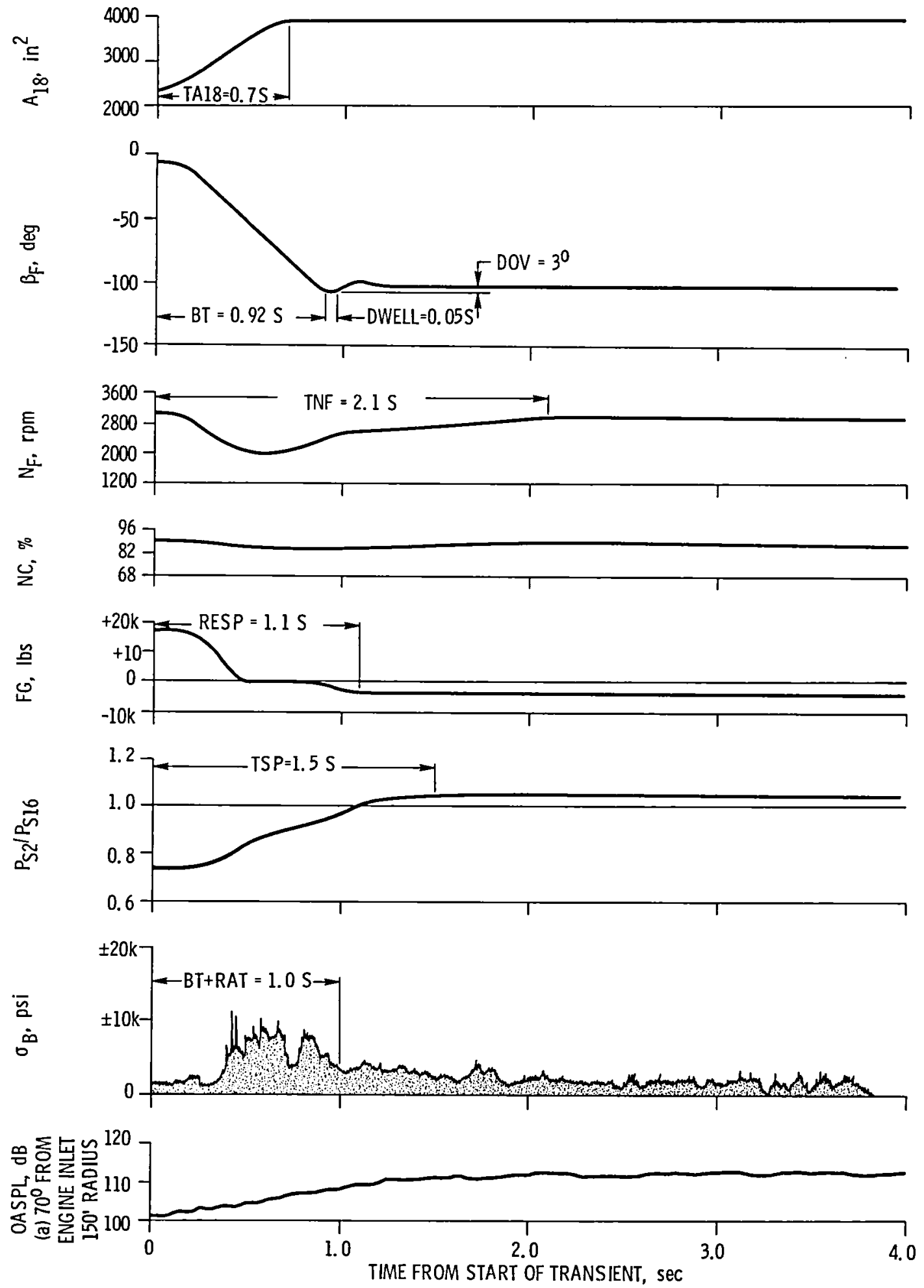

Figure 29. - Takeoff-to-reverse transient (\#13) with no blade overshoot. 

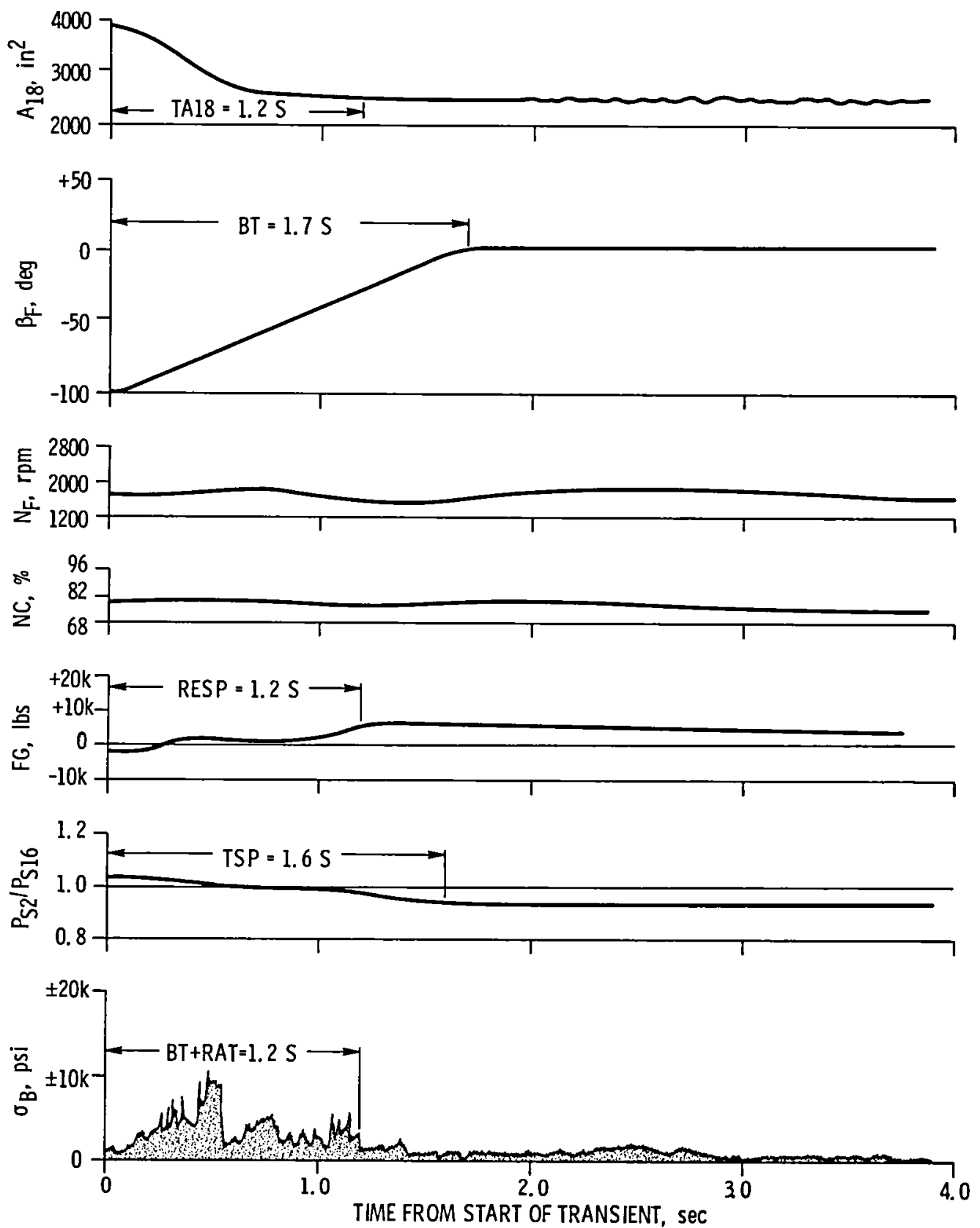

Figure 30. - Typical reverse idle-to-forward idle transient. 
TRANS BLADE FUEL INITIAL (FWD) FINAL (REV)

\# OVER - INTER - $\beta_{F} \quad N_{F K}$ FGK $\beta_{F} N_{F K}$ FGK SHOOT LOCK deg $\%$ lb deg $\%$ lb

$\begin{array}{rlllllll}5 & \text { NO } & -90 & +5.356 .5 & 4546 & -101.6 & 90.5 & -4626\end{array}$

$13 \quad$ NO $\quad-70 \quad-7.295 .517136-101.589 .5-4607$

$15 \quad$ NO $\quad-70+3.188 .510632-96.881 .2-4945$

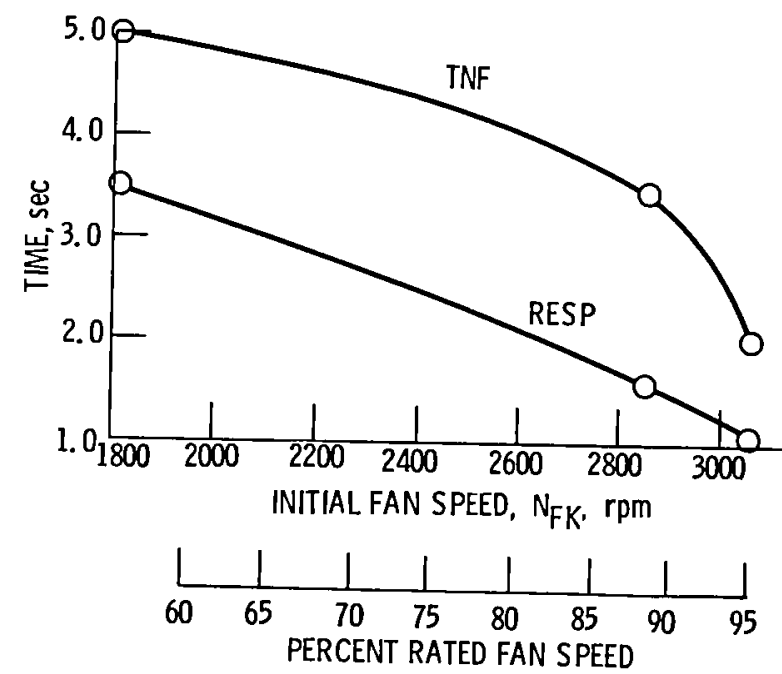

Figure 31. - Effect of initial fan speed on response characteristics during forward-to-reverse transient.

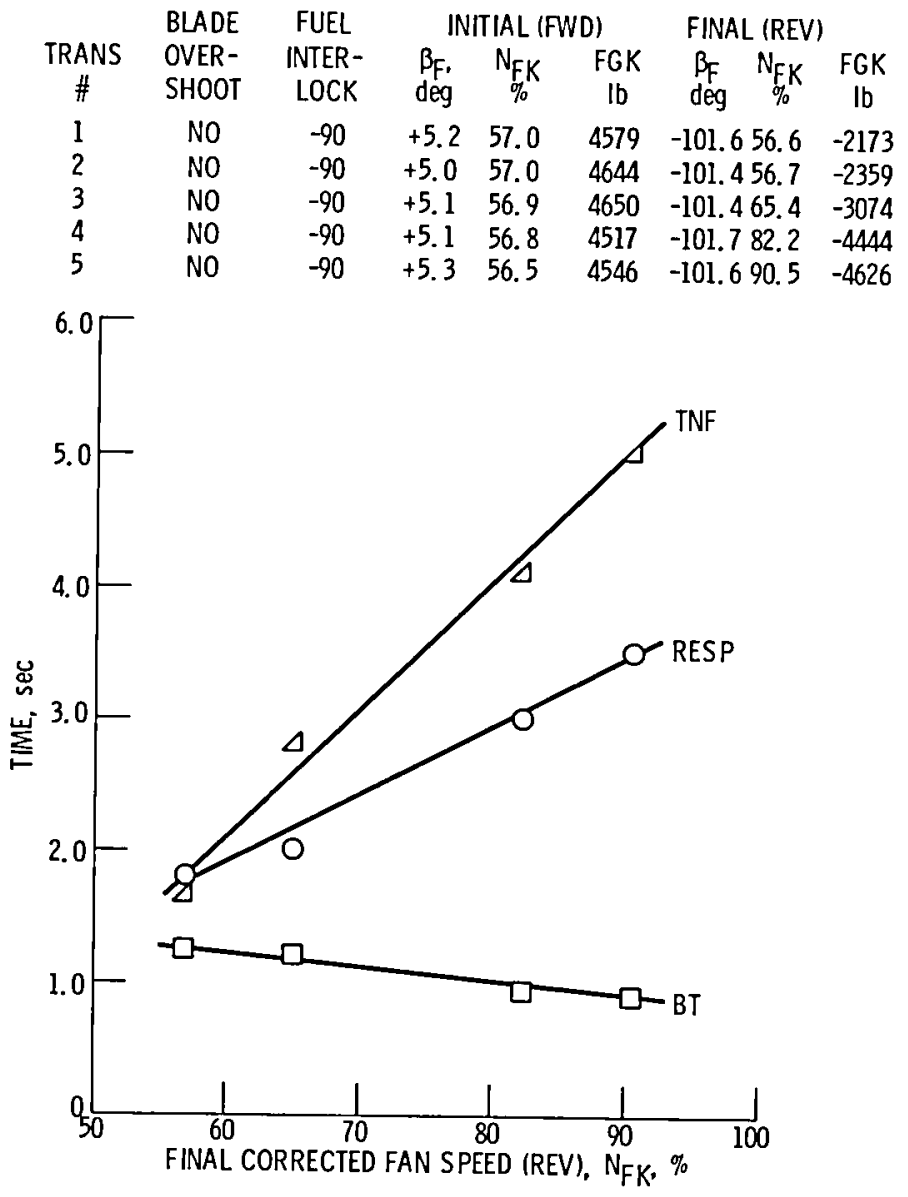

Figure 32. - Effect of final final fan speed on response characteristics. 


\begin{tabular}{ccccccccc} 
TRANS & BLADE & FUEL & \multicolumn{4}{c}{ INITIAL (FWD) } & \multicolumn{3}{c}{ FINAL (REV) } \\
$\#$ & OVER- & INTER- & $\beta_{F}$ & $N_{F K}$ & FGK & $\beta_{F}$ & $N_{F K}$ & FGK \\
& SHOOT & LOCK & deg & $\%$ & lb & deg & $\%$ & lb \\
7 & NO & -70 & +2.3 & 88.2 & 10662 & -101.4 & 89.8 & -4506 \\
10 & NO & -70 & +2.4 & 88.1 & 10750 & -111.7 & 89.7 & -2350 \\
12 & NO & -70 & +2.5 & 88.2 & 10768 & -106.7 & 89.8 & -3400 \\
$13 A$ & YES & -70 & +3.0 & 88.0 & 10765 & -87.0 & 80.9 & 0
\end{tabular}

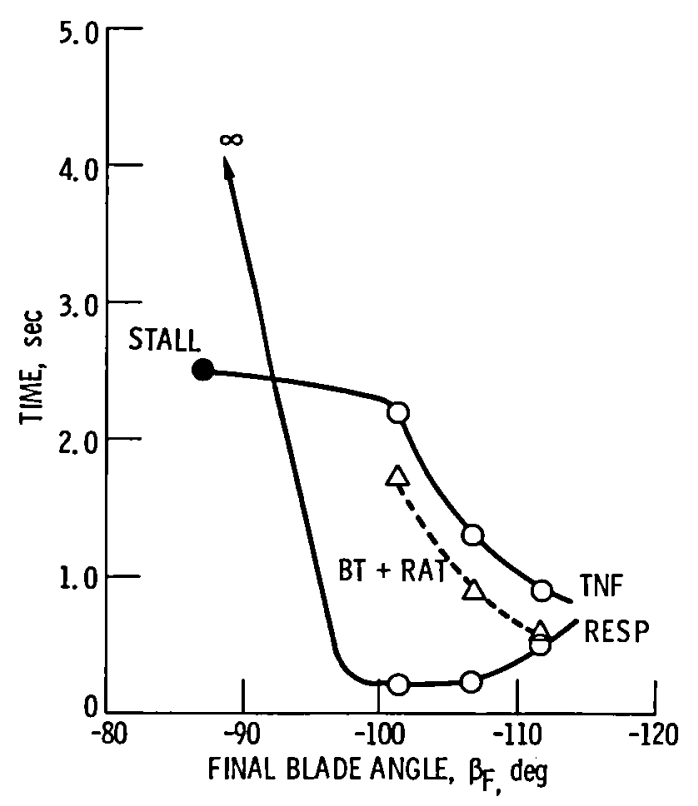

Figure 33. - Effect of final blade angle on response characteristics during approach-to-reverse transients.
TRANS BLADE FUEL INITIAL (FWD) FINAL (REV)

\# OVER - INTER - $\beta_{F} N_{F K}$ FGK B N NK FGK

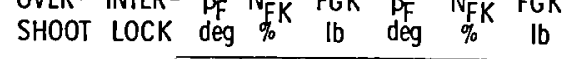

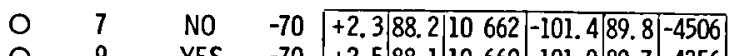
\begin{tabular}{llll|l|l|l|l|l|l|l|l|l|l|l|l|l|}
0 & 9 & YES & -70 & +2.5 & 88.1 & 10 & 660 & -101.9 & 89.7 & -4256
\end{tabular}

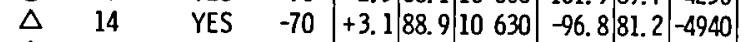
$\begin{array}{llllllllllll}\Delta & 15 & N 0 & -70 & +3.1 & 88.5 & 10 & 632 & -96.8 & 81.2 & -4945\end{array}$

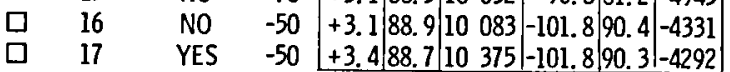
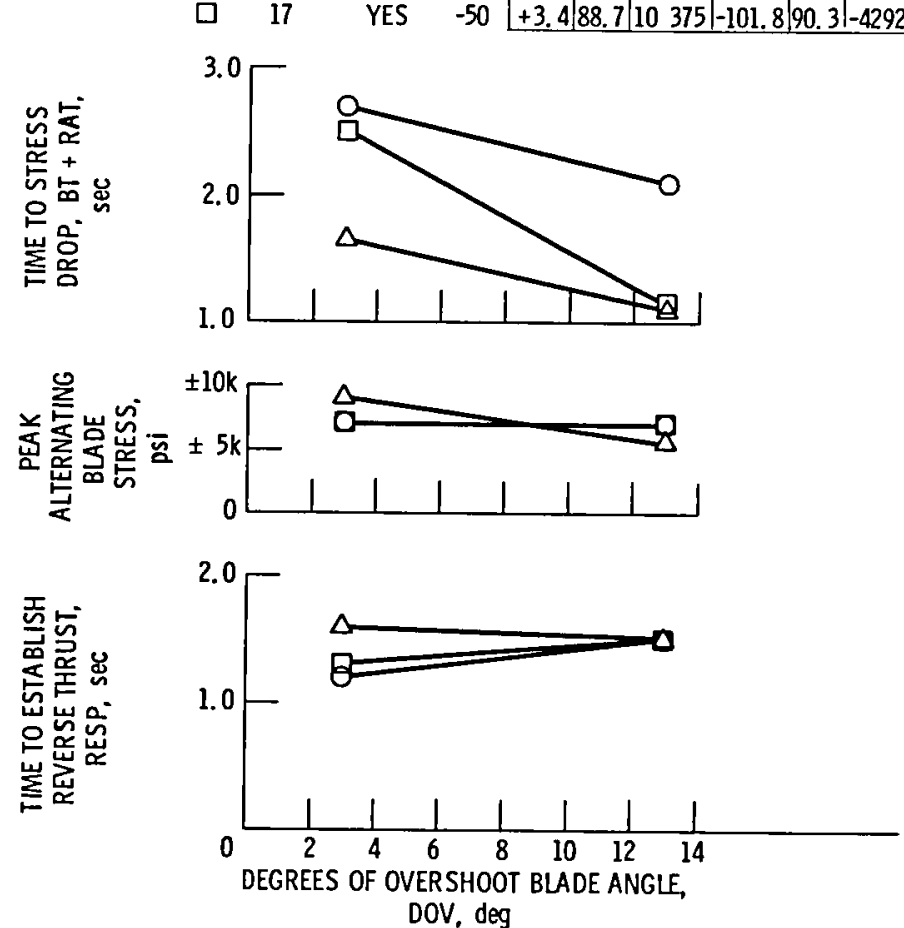

Figure 34. - Effect of fan blade overshoot on thrust response and blade stress characteristics during forward-to-reverse transient. 

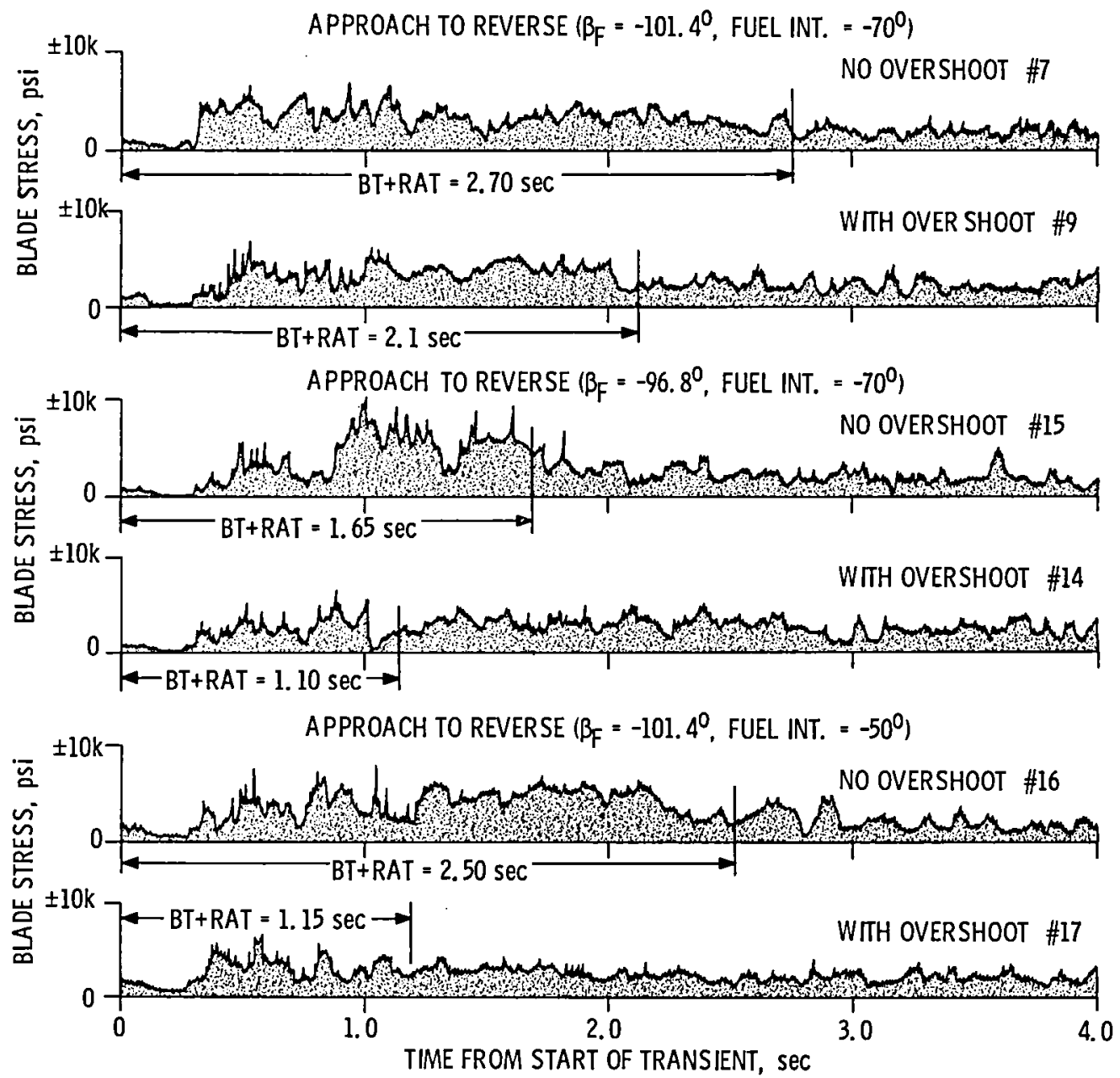

Figure 35. - Fan blade stress during forward-to-reverse transient with and without blade overshoot. 


\begin{tabular}{ccccccccc} 
TRANS & BLADE & FUEL & \multicolumn{3}{c}{ INITIAL (FWD) } & \multicolumn{2}{c}{ FINAL (REV) } \\
$\#$ & OVER- & INTER- & $\beta_{F}$ & $N_{F K}$ & FGK & $\beta_{F}$ & $N_{F K}$ & FGK \\
& SHOOT & LOCK & deg & $\%$ & Ib & deg & $\%$ & I b \\
6 & NO & -90 & +2.6 & 88.5 & 10077 & -101.489 .9 & -4474 \\
7 & NO & -70 & +2.3 & 88.2 & 10662 & -101.489 .8 & -4506 \\
8 & NO & -60 & +2.5 & 88.3 & 10683 & -101.789 .7 & -4695 \\
16 & NO & -50 & +3.1 & 88.9 & 10083 & -101.8 & 90.4 & -4331
\end{tabular}
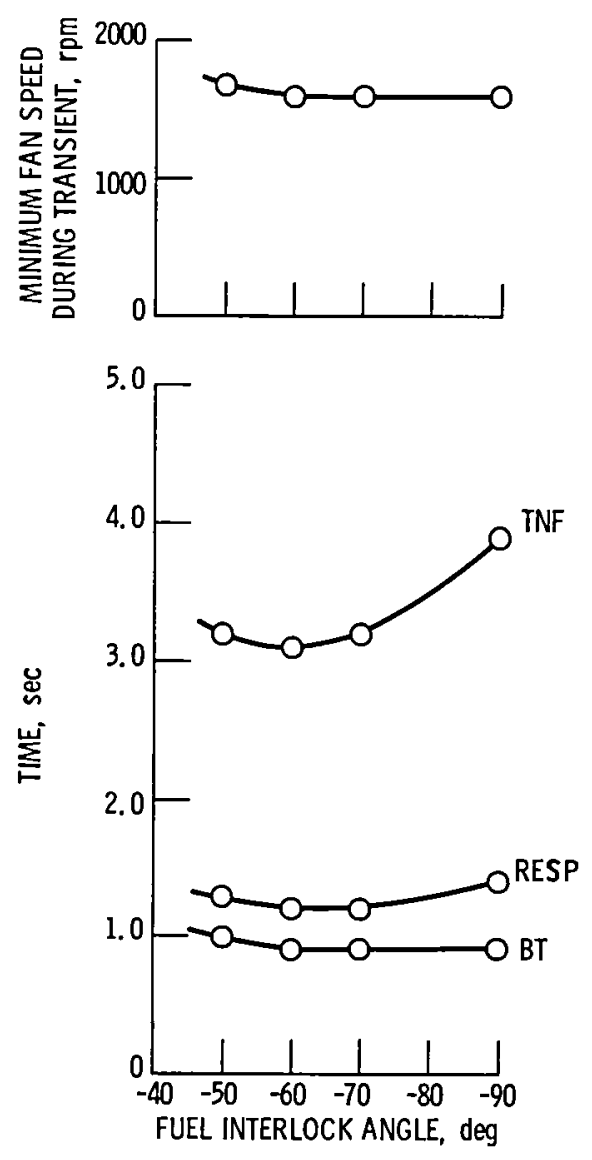

Figure 36. - Effect of fuel scheduling during forward-to-reverse transient on fan speed excursions and response characteristics. 


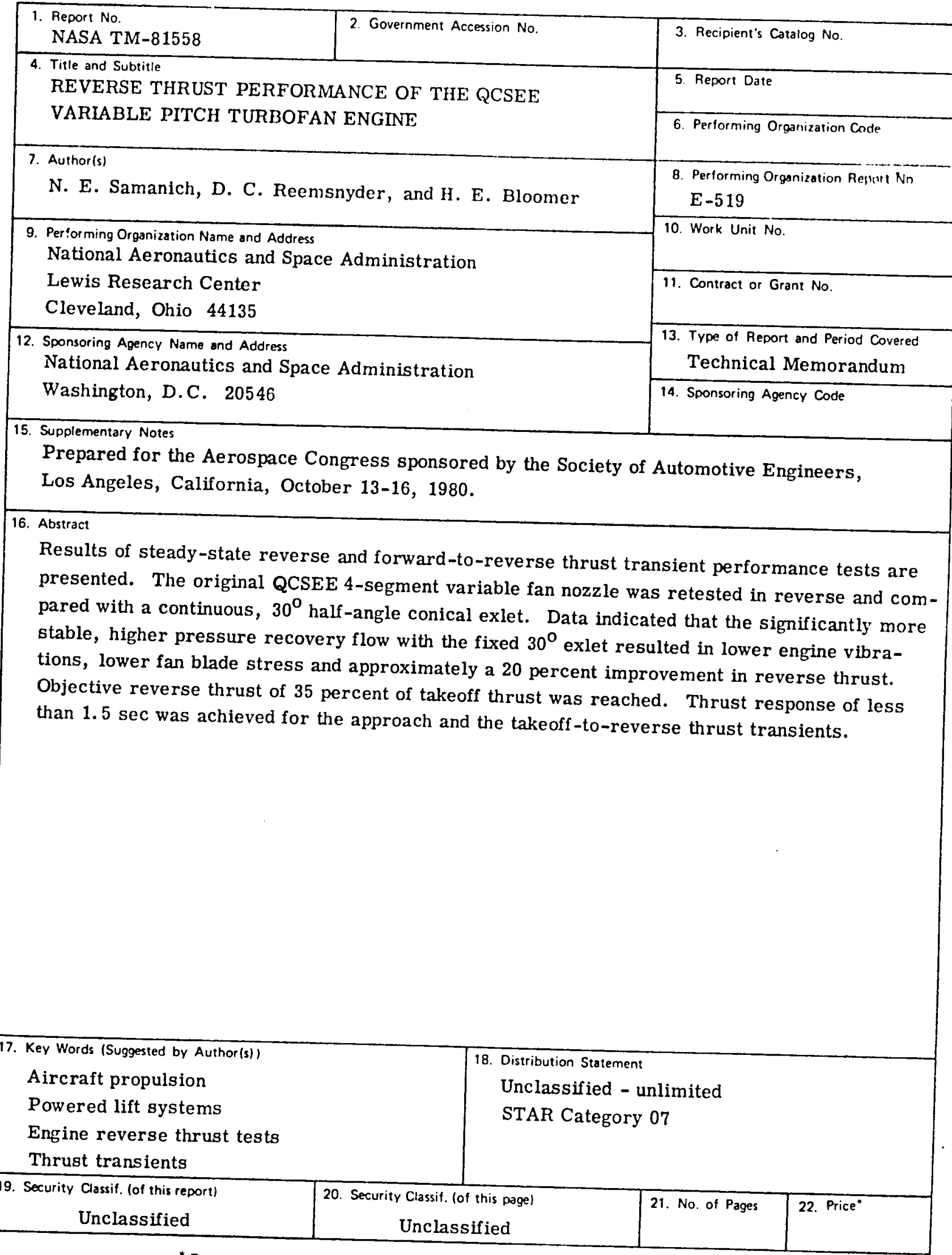

* For sale by the National Technical Information Service, Springfield, Virginia 22161 
$\because$ 
National Aeronautics and Space Administration

Washington, D.C.

20546

Official Business

Penalty for Private Use, $\$ 300$
SPECIAL FOURTH CLASS MAIL BOOK

3 1176013249686
Postage and Fees Paid National Aeronautics and Space Administration NASA-451

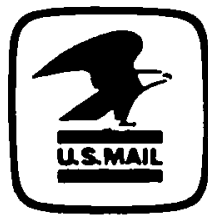

